\title{
Network Structure and Strategic Investments: An Experimental Analysis
}

\author{
Stephanie Rosenkranz* and Utz Weitzel $^{+}$ \\ *Utrecht University School of Economics, and CEPR \\ ${ }^{+}$Utrecht University School of Economics
}

May 2008

\begin{abstract}
This paper analyzes the effects of network positions and individual risk attitudes on individuals' strategic decisions in an experiment where actions are strategic substitutes. The game theoretic basis for our experiment is the model of Bramoullé and Kranton (2007). In particular, we are interested in disentangling the influence of global, local and individual factors. We study subjects' strategic investment decisions in four basic network structures. As predicted, we find that global factors, such as the regularity of the network structure, influence behavior. However, we also find evidence that individual play in networks is to some extent boundedly rational, in the sense that coordination is influenced by local and individual factors, such as the number of (direct) neighbors, local clustering and individuals' risk attitudes.
\end{abstract}

Keywords: Social networks, experiment, coordination, strategic substitutes, risk aversion

JEL classification: C91, D00, D81, D85, C72, H41

* Corresponding author: Utrecht University School of Economics, Janskerkhof 12, 3512 BL Utrecht, The Netherlands, s.rosenkranz@econ.uu.nl. We are grateful for the comments and discussions with Rob Alessie, Vincent Buskens, Sanjeev Goyal, Kris de Jaegher, Jurjen Kamphorst, Marco van der Leij and Bastian Westbrock. Furthermore we thank colleagues from USE, the participants of CTN workshop 2007 in Louvain-la-Neuve, the ESEM 2006 in Madrid, the CREED research seminar in Amsterdam for their helpful comments on an earlier version of this paper, which was based on a pilot experiment. All errors are ours. 


\section{Introduction}

Although the traditional economics model yields a number of powerful insights about implications of rational decisions for resource allocation and welfare, it seems not to be able to explain some tenacious empirical regularities, like persistent inequalities, patterns of technology diffusion, or sociological phenomena like segregation of neighborhoods. In the recent past the traditional model of human activities, occurring within markets with anonymous and centralized interaction, has been further developed to also take into account the network in which the actors are embedded. In fact, the economics of social networks has gained increasing attention in the past decade, manifested in an explosion of game theoretical models on formation, stability and efficiency of networks and the "wide variety of settings where social networks play a role [still] leads to an almost endless set of interesting avenues to investigate" (Jackson 2005, p.59). As predictions from models proliferate, we need to confront these with rigorous empirical tests not only to deduct a more general theory, but also to identify the conditions under which factors on the individual, the local and the global level influence human activities. As interactions on networks easily become complex it is not evident to what extent and under which conditions individual behavior is in fact influenced by global graph theoretical properties of the network and how their influence interact with factors on the local or on the individual level. For economics of social networks "[e]xperiments provide an important test bed for results which can be very difficult to pinpoint outside of the controlled environment of a laboratory" (Jackson 2005, p.60).

We conduct the first of such a test for the model of Bramoulle and Kranton (2007). Their network model pictures innovative activities and was motivated by the empirical analysis of Foster and Rosenzweig (1995), who study farmers' experimentations with a new technology. They find evidence of free riding as farmers tend to experiment less when their neighbors experiment more. Bramoullé and Kranton (2007) present a model in which individuals are part of a network and invest in the production of a local public good, as e.g. the farmers invest into the production of know-how. The underlying idea is that such innovative activities of individuals have positive externalities and that those externalities are strongest for those that are "closest" to the innovator. In general being "close" can have different meanings in different contexts: within organizations being "close" would refer to those who collaborate in the same project, in markets that could refer to all those that are part of an alliance, or to those who have access to the innovator's know-how due to, e.g., geographical or social proximity. All those interpretations are possible when explicitly considering the (social) network of the innovator.

Bramoullé and Kranton (2007) provide one of the first analysis of a game played on a network when actions are strategic substitutes. The model is characterized by two main features: agents are embedded in a fixed social 
network, and agents' payoffs are directly affected by their partners' actions. Most papers sharing these two assumptions look at positive social interactions and coordination games. In contrast, in their paper, Bramoullé and Kranton (2007) study a game with features of an anti-coordination game. Their analysis leads to several insights. First, they find that social networks can lead to specialization and that in any network there is an equilibrium where some individuals invest into innovative activity while others completely rely on the efforts of the innovators. Furthermore, "in many, particularly asymmetric, networks this extreme form of free-riding is the only equilibrium outcome. In all networks, such patterns are the only stable outcomes. Hence, an agent's position in a network can determine whether or not he contributes to the public good." (Bramoullé and Kranton (2007, p.479).

We designed an experiment to explicitly address and identify the conditions under which individual, local and global factors influence innovative activities. We test hypotheses derived from the model of Bramoulle and Kranton (2007) for the impact of global factors. First we test whether individuals indeed are able to coordinate on equilibria. Here we find that individuals do play equilibrium strategies but that the extent to which they are able to do this is strongly influenced by the network structure. In a highly centralized structure we find that $20.9 \%$ of all decisions can be labeled as reflecting local coordination, as opposed to only $5.4 \%$ in the full network. Then we test whether play converges to the theoretically predicted stable equilibria if they exist. Theory predicts for two of our experimental structures stable specialized equilibria. We find that overall stability is very low. However, if play converges then it does so towards the predicted equilibria.

Furthermore we test whether equilibrium play is hampered by an increasing number of neighbors in regular networks, and whether the extent of specialization is related to centralization in irregular networks. Here we find that, while density is significantly negatively related to local coordination in regular structures, it seems more difficult to coordinate on an equilibrium if transitivity is low: we find that individuals have huge coordination problems when located in a circle. For irregular structures we did not find evidence for the effect of centralization on the extent of specialization, although we found significantly less free riding and more full investment in the star than in a core-periphery network.

As influencing factors on the local level we consider an agent's degree (the number of direct neighbors) and node transitivity (local clustering), the extent to which an agent's neighbors are connected to each other. We derive the hypothesis on the effect of the number of neighbors from Galeotti et al. (2006) and from Chamberlin (1974). In line with those theoretical considerations we expect an agent's investment to decrease in the number of neighbors. For the effects of transitivity (local clustering) theoretical predictions are ambiguous and also previous experimental predictions are less evident. We derive our hypothesis from discussions in Galeotti et al. 
(2006) and findings of the experiment of Cassar (2007). We find strong evidence for a negative relation between an agent's degree and investment as well as between local clustering and investment.

A specific feature present in the model of Bramoullé and Kranton (2007) is the fact that all network structures support multiple equilibria, with a tendency that the denser and the more symmetric the structure the larger the number of equilibria. This adds a significant amount of strategic uncertainty to individual agents. We therefore hypothesize that, next to global factors and to local features of a specific network position, personal risk attitudes also have an impact on strategic investment. Relating to the theory of global games as one of the more recent theoretical refinement concepts, we consider players' subjective beliefs about other players' actions and find that individual investments increase in a player's risk aversion. ${ }^{1}$ Hence, we expect to find that risk aversion leads to overinvestment. This relation is not supported in our experiment. We find specifically for regular structures that relatively risk averse individuals invest less.

Altogether we find that global, local and individual effects coexist and that decision making by individuals is strongly affected by the structure of their local neighborhood. This suggests that individual play in networks is boundedly rational, in the sense that coordination is significantly influenced by local and individual factors. This result contributes to the understanding of individual behavior in social contexts. Particularly, it suggests that theory may focus on models with incomplete information about the global structure. With the finding that the global network structure only partially determines behavior, the paper also indicates that valuable predictions can be derived from theoretical models that are confined to the analysis of very simple, local structures as the basic building blocks for more complex networks.

The rest of the paper is structured as follows: In the next section we briefly relate or work to the existing literature. Then we present the theoretical foundation and the hypotheses that we aim to test in the experiment. In Section 4 we present the experimental design, in Section 5 the results, and we conclude in Section 6 .

\section{Literature}

While theoretical research on economic networks has received extensive interest in the past 15 years, experimental work on networks in economics has been neglected until recently. ${ }^{2}$ The existing experiments can broadly be grouped according to their focus on the effect of network structures on equilibrium selection, or on cooperation, or on link formation and the evolution

\footnotetext{
${ }^{1}$ On global games see Carlsson and van Damme (1993) and Morris and Shin (2000).

${ }^{2}$ See Kosfeld (2004) for an interesting survey on experimental contributions in that field.
} 
of networks.

The first group of experiments is based on seminal work by Kandori, Mailath, and Rob (1993) and Young (1993), who have triggered intense interest in the question of equilibrium selection in coordination games. Berninghaus et al. $(1998,2002)$ present the first experiments that consider the role of the global structure of networks in coordination games. In their experiment, agents are located on a circle, and on a two-dimensional lattice, and while the size of an agent's neighborhood remains constant across treatments, the neighborhood structure differs. The authors find that play is more likely to converge to the risk-dominant equilibrium when agents interact on the lattice than on the circle. This result is rather striking since subjects were not informed about the precise global structure of the population in the two treatments. The authors conjecture that subjects observe individual play to be more changing in the lattice treatment than in the circle treatment and that therefore risk dominance as an individual motive has more power in the lattice treatment than in the circle treatment. Boun My et al. (2001) also analyze the effect of network structure on equilibrium selection. Using a setting similar to Keser et al. (1998), they compare the repeated play of a $2 \times 2$ coordination game under global and under local interaction with varied degrees of risk dominance of the inefficient equilibrium. In their setting the interaction structure itself does not seem to play a significant role in the convergence of play. In particular, contrary to the studies described above, Boun My et al. do not find that agents who interact locally on the circle coordinate more frequently on the risk-dominant equilibrium. Ellison (1993) and Morris (2000) analyze theoretically the role of local interaction networks in the spread of particular strategies in simple coordination games, showing how play converges to the risk-dominant equilibrium if players are located on a circle and interact with their two nearest neighbors. Blume (1993) and Kosfeld (2002) prove empirically that under certain conditions there is convergence to the risk-dominant equilibrium in a population of players located on a d-dimensional lattice.

A second group of experiments focuses on cooperation in networks. Recently Kirchkamp and Nagel (2007) investigated the effect of local interaction on learning and cooperation in repeated prisoners' dilemmas. They compare interaction neighborhoods of different size and structure, and observe choices under different information conditions. Interestingly their experimental findings contradict the theoretical predictions of naive imitation models. Cassar (2007) studies coordination games and prisoners' dilemmas in local, random and small-world networks. She finds a tendency for coordination on the payoff-dominant equilibrium in all three networks. Her results suggest that local interactions do cause faster coordination than random interactions, but do so on the payoff-dominant equilibrium rather than on the risk-dominant equilibrium. ${ }^{3}$ For the cooperation game, she finds insufficient

\footnotetext{
${ }^{3}$ There is an interesting as well as promising link of research on coordination in social
} 
cooperation in all three networks, with average cooperation lower in smallworld networks than in random and local networks which seems to support the prediction of Eshel et al. (1998) that local interactions offer a better ground for cooperation than other networks.

A third line of experiments investigates individual incentives for network formation. Goeree et al. (2008) analyze a pure network formation game and find that equilibrium predictions fail completely with homogeneous agents, while heterogeneity fosters the formation of an efficient structure over time. Buskens et al. (2007) find some evidence that subjects will form networks that lead to play of the efficient Nash equilibrium in a simple coordination game, if they can choose their network partners themselves.

Results of the experiments so far have shown that network configurations have important effects on economic outcomes, such as the convergence towards equilibria, the support of Pareto superior states, or the distribution of surplus among economic agents. We contribute to this research by focusing on the effect of network configurations on individual investment decisions in games with strategic substitutes.

\section{Predictions for strategic investment in local pub- lic goods}

In this section we briefly summarize the model and findings of Bramoullé and Kranton (2007) and translate them into testable hypothesis. Suppose there is a set of agents $N=\{1, \ldots, n\}$ and let $e_{i} \in \mathbb{R}^{+}$denote agent $i$ 's level of effort spend on the production of a local public good.

Agents are arranged in a network which is represented by an undirected network $g$, that is: $g_{i j} \in\{0,1\}, g_{i j}=g_{j i}$, for all $j \in N$. If $g_{i j}=1$, agent $j$ benefits directly from agent $i$ 's production, and $g_{i j}=0$ otherwise. Agent $i$ benefits from his own effort, thus $g_{i i}=1$. Let $N_{i}=\left\{j \in N \backslash\{i\}: g_{i j}=1\right\}$ be the set of agents with whom agent $i$ has a link in the network $g$, and let $\eta_{i}(g)=\left|N_{i}(g)\right|$ denote the cardinality of this set. We refer to $\eta_{i}(g)$ as agent $i$ 's degree and to $N_{i}$ as the neighbors of agent $i$ that benefit directly from $i$ 's effort. A network is regular if every agent has the same number of links, i.e., $\eta_{i}(g)=\eta(g) \forall i \in N$. We refer to $\eta(g)$ as the density of the network (average degree) and to $\eta\left(g^{c}\right)$ as the number of links that are maximally possible in the set of agents $N$. Each agent receives a benefit $u_{i}\left(e_{i}, \ldots, e_{n} ; g\right)=$ $b\left(e_{i}+\sum_{j \in N_{i}} e_{j}\right)$ with $b(0)=0$ and $b^{\prime}>0$ and $b^{\prime \prime}<0$. Marginal costs of effort are constant and equal to $c$ and we assume $b^{\prime}(0)>c$ to avoid trivial cases.

Given this set-up, Bramoullé and Kranton (2007) study which investment levels form equilibria given a network structure. Let $e^{*}$ denote the

networks to recent theoretical and experimental studies on strategic uncertainty, e.g., by Heineman, Nagel and Ockenfels (2004a) and (2004b). 
effort level at which to an individual agent, marginal costs are equal to marginal benefits. Bramoullé and Kranton (2007) model the investment decisions on a given network as a non-cooperative game. All individuals simultaneously decide how much to spend on the production of the local public good. It is straightforward to show that a profile e is a Nash equilibrium if and only if for each agent $i$ either (1) $\sum_{j \in N_{i}} e_{j} \geq e^{*}$ and $e_{i}=0$, or (2) $\sum_{j \in N_{i}} e_{j} \leq e^{*}$ and $e_{i}=e^{*}-\sum_{j \in N_{i}} e_{j}$. Obviously, levels of effort are strategic substitutes; the more one agent invests the less invest his direct neighbors. In general, the equilibrium distribution of effort will lie in-between two extremes: either a profile e is such that for all agents $i$ either $e_{i}=0$ or $e_{i}=e^{*}$. This will be called a specialized profile, and furthermore we will call an agent who invests $e^{*}$ a specialist and an agent investing $e=0$ a free-rider. The other extreme is that all agents $i$ invest some effort such that $0<e_{i}<e^{*}$. This will be called a distributed profile. In order to gain some intuition for this model we ask the reader to refer to section 4.1, where a specific functional form for the benefit function is presented and equilibrium outcomes for four network structures (those used in the experiment) are characterized.

The first set of hypotheses are formulated under the assumption that agents behave perfectly rational in the sense that they are aware of the entire network structure and that their behavior is influenced by the graph structural properties at the group level. For our analysis the following general result of Bramoullé and Kranton (2007, Theorem 1, and footnote 10, p. 483) is of direct interest: For any structure g, there exists a profile e that constitutes a Nash equilibrium, and for any structure $\mathrm{g}$, there exists a specialized profile e that constitutes a Nash equilibrium (Theorem 1, p. 483). This result implies that we can characterize best-response functions as well as equilibria for specific network structures. Since pure strategy equilibria exist for all network structures, we can hypothesize that in each network structure individuals are able to find, and thus with some probability coordinate on, pure strategy equilibria.

(H1) In any network structure individuals are able to coordinate on pure strategy equilibria.

Furthermore, using a simple notion of stability based on Nash tâtonnement, Bramoullé and Kranton (2007, Theorem 2, p. 484) identify stable structures: For any social structure $\mathrm{g}$, an equilibrium is stable if and only if it is specialized and every non specialist is connected to (at least) two specialists. This second result implies that if a network structure allows for an equilibrium as specified in the theorem, play should converge towards this equilibrium.

(H2) Equilibria in which every non-investing agent is connected to at least two specialists are reached with higher probability and are played for a higher number of rounds than other equilibria. 
Moreover, in an earlier version of the model, Bramoullé and Kranton (2005) derive some results that concern specific structures. One result concerns symmetric regular structures (overlapping neighborhoods graphs) in which each agent has $k$ neighbors on the left and $k$ neighbors on the right: In an overlapping neighborhood graph of size $k$, (a) a strategy profile e is a distributed equilibrium if and only if there exists a common divisor of $n$ and $2 k+1$ - which we denote $m$ - such that the sequence of the first $m$ effort levels $\left(e_{1}, \ldots, e_{m}\right)$ satisfies $\sum_{i=1}^{m} e_{i}=\frac{m}{2 k+1} e^{*}$ and the profile e $i s$ a repetition of this sequence for every $m$ agents. In particular, the profile where every agent invests $\frac{1}{2 k+1} e^{*}$ is an equilibrium $(m=1)$. (b) A strategy profile is a specialized equilibrium if and only if the distance between two consecutive specialists is at least $k+1$ and no more than $2 k+1$. (Bramoullé and Kranton (2005), p. 14)

From this finding we can conclude that in symmetric regular networks coordination becomes easier the lower the density, (note that there are just two equilibria in a circle as opposed to infinitely many in the full network). Hence, we should observe more coordination in regular networks with a lower degree. We translate this into the following hypothesis:

(H3) In regular networks the probability to coordinate on an equilibrium decreases with the (average) degree.

Another theoretical result refers to irregular structures: On any coreperiphery graph, there are two types of Nash equilibria: (a) No p-core agent (a core agent that has one or more links to peripheral agents) exerts effort, each peripheral agent exerts $e^{*}$, and the other core agents collectively exert a total effort of $e^{*}$. (b) One p-core agent is a specialist and invests $e^{*}$, all his neighbors (the rest of core and his links in the periphery) do not exert effort, and the remaining peripheral agents each exert $e^{*}$. (Bramoullé and Kranton (2005), p. 21)

This finding can be translated into predictions for specific structures: we should not find distributed equilibria in a core-periphery graph with just one p-core agent (star network), while in core-periphery graphs with core agents without links to periphery agents, we should observe distributed equilibria. We thus formulate the next hypothesis as follows:

(H4) The probability to play specialized (maximum effort or perfect free-riding) is higher in star networks than in core-periphery networks.

We consider connected graphs, i.e. networks in which each agent directly interacts with a selected group of population members, his neighbors, and where all agents' neighbors are overlapping such that no group of the population can split off from the rest of the population. As a consequence, each agent interacts directly with his neighbors and indirectly with the whole population. Under the assumption of full rationality this would mean that 
agents' actions directly depend on the number of their direct neighbors, the number of neighbors' neighbors, etc. ... . Following Stahl and Wilson (1995) and Costa-Gomes et al. (2001), we may alternatively assume that some agents follow certain kinds of boundedly rational decision rules. In our network setting this would imply that agents are able to internalize the network structure up to a limited distance only, and formulate their optimal response accordingly. For the following hypotheses we therefore take the view that the direct influence from the local interaction with the neighbors outweighs the indirect influence of the global interaction.

Given this view, we can formulate hypothesis on the influence of graph structural properties at the local level (characteristics of the direct neighborhood) on an agent's behavior. On the local level an agent's degree $\eta_{i}(g)$ (or degree centrality $\left.\frac{\eta_{i}(g)}{\eta\left(g^{c}\right)}\right)$ and transitivity (local clustering), i.e. the extent to which an agent $i$ 's neighbors are connected to each other, will have influence on behavior. Following Jackson (2005) we measure an agent $i$ 's transitivity (local clustering) as: ${ }^{4}$

$$
C_{i}(g)=\frac{\#\left\{g_{j k} \in g \mid k \neq j, j \in N_{i}, k \in N_{i}\right\}}{\#\left\{g_{j k} \mid k \neq j, j \in N_{i}, k \in N_{i}\right\}} .
$$

Theorists and experimentalists have analyzed the effects of group size on contributions to public goods in general (see Chamberlin (1974) and for an overview of experiments Kagel and Roth (1995)) and the effect of degree on coordination in networks (see, e.g., Berninghaus, Ehrhart and Keser (2000) as well as Berninghaus and Schwalbe (1996)) in specific. In the above characterized setting production of the local public good is an inclusive and inferior collective good. ${ }^{5}$ From the analysis of Chamberlin (1974) follows that individual investment should be decreasing with the group size (degree) while total investment should be unaffected.

Exact predictions on how the effect of an agent's degree on investment depends on the local network structure can be derived from the model of Galeotti et al. (2006) in which agents are assumed to have incomplete information on the networks structure. Galeotti et al. (2006) show that, under incomplete information, in every (symmetric) equilibrium, actions are increasing (decreasing) in an agent's degree if neighbors' actions are strategic complements (substitutes). Furthermore they show that degreemonotonicity properties can be violated under complete information. If we assume that agents' investment decisions are in fact less affected by global graph structural properties of the network and more by those at the local level, these theoretical findings lead us to the following hypothesis:

\footnotetext{
${ }^{4}$ For agents with only one neighbor, implying that the denominator of $C_{i}(g)$ is 0 , we follow Jackson (2005) and adopt the convention of setting $C_{i}(g)=1$.

${ }^{5}$ Note that in Bramoullé and Kranton (2007) investing effort into know-how production is inclusive as the individual reaction functions are independent of the number of neighbors. It is an inferior good because the slope of the reaction functions is negative and $\geq-1$.
} 


\section{(H5) An individual's investment decreases in his degree.}

Note that this hypothesis is based on two considerations. The more neighbors an agent has the more likely is miscoordination and thus the more likely it is that some neighbors will invest a positive amount. The larger the number of neighbors the more likely it is that their investment sums up to the optimal level.

For the effects of local clustering theoretical predictions are ambiguous and experimental predictions for related strategic situations do not exist. Obviously, as explained by Galeotti et al. (2006), the incentives of an agent depend on the expected probability that each of his neighbors provides the public good. The source of complication lies in the aspect that an increase in degree of a neighbor (on average) implies a decline in her investment (on average), which in our setting of strategic substitutes suggests that the best response of an agent should be to increase effort. But if ultimately the probability of each agent choosing high effort rises, the incentives to choose high effort for each agent are lower, which would generate an inconsistency.

Cassar (2007) finds in her (remotely related) experiment that local clustering has a negative effect on coordinating on the payoff dominant action in a coordination game while it has no significant effects on choosing the cooperative action in the PD game. Contrary to this, global clustering has a positive effect on the coordination on the dominant action. On the basis of these findings we formulate the following hypothesis:

(H6) An individual's investment decreases with local clustering among agents.

Moreover, the model predicts multiple equilibria for all network structures. Hence agents will be confronted with strategic uncertainty, since they cannot assign probabilities to any outcome by relying only on deductive reasoning. All outcomes are consistent with optimizing behavior and rational expectations so that neoclassical theory cannot help to predict behavior.

Theoretical refinement concepts are based on assumptions on players' beliefs about other players' behavior. One such concept is the theory of global games proposed by Carlsson and van Damme (1993). ${ }^{6}$ In what follows we use ideas from their approach and link individual investment in

\footnotetext{
${ }^{6}$ The theory of global games starts from an environment of incomplete information about economic fundamentals.

In a global game setting, there is a unique equilibrium where each player chooses the action that is a best response to a uniform belief over the proportion of his opponents choosing each action. Thus, when faced with some information about the underlying state of the world, each player hypothesizes that the proportion of other players who will opt for a particular action is a random variable that is uniformly distributed over the unit interval and chooses the best action under these circumstances. This approach, further advanced by Morris and Shin (2002), generates predictions for games with strategic complementarities (in which equilibria can be ranked), and Harrison (2003) developed it further for games with strategic substitutabilities in which players can be ranked. Hellwig
} 
the above described network games to a player's position in a network and his degree of risk aversion. Suppose first that we can characterize a player $i^{\prime} s$ utility from the investment by his degree of risk aversion $r_{i}$, given the realized investments of his neighbors $\sum_{j \in N_{i}} e_{j}$, such that $U\left(e_{i}, g, r_{i}\right)=$ $b\left(e_{i}+\sum_{j \in N_{i}} e_{j}, r_{i}\right)-c e_{i}$ with $\partial^{2} b\left(\cdot, r_{i}\right) / \partial e_{i} \partial r_{i}>0$ which implies together with the assumptions on $b(e)$ that $\frac{\partial e_{i}^{*}}{\partial r_{i}}>0$ for given $\sum_{j \in N_{i}} e_{j}$. Suppose for simplicity that each player has a binary decision to either invest as a specialist or to be a free rider, i.e., $e_{i} \in\{0,1\}, \forall i \in N$. Define a belief $p$ that a randomly selected neighbor $j$ of player $i$ in network $g$ is investing as a specialist (hence, $e_{j}=e^{*}$ ). A player $i$ with degree of risk aversion $r_{i}$ will find it optimal to play 1 , whenever he believes that no other player in his neighborhood will play 0 with a probability at least as large as $(1-p)$, and he will prefer 0 , whenever his belief that other player plays 0 falls below $(1-p)$. Player $i$ is indifferent between investing and not investing if:

$$
(1-p)^{N_{i}} b\left(e^{*}, r_{i}\right)+\left(1-(1-p)^{N_{i}}\right) b\left(2 e^{*}, r_{i}\right)-c e^{*}=\left(1-(1-p)^{N_{i}}\right) b\left(e^{*}, r_{i}\right)
$$

Define $p\left(N_{i}, r_{i}\right)$ as the solution to this equation. For given values of $N_{i}$ we find that $p\left(N_{i}, r_{i}\right)$ is increasing in $r_{i}$; hence, the more risk averse a player is the higher has to be his belief that the other players play 1, in order to induce him to play risky, $e_{i}=0 .^{7}$ And the higher his ex post expected return to playing 0 , the lower the threshold probability at which $e_{i}=0$ becomes optimal. We translate this argument into our final hypothesis:

(H7) A risk averse agent should invest more than a risk seeking agent.

\section{Design of the Experiment}

\subsection{Experimental game}

The aim of our experimental design is to test the hypotheses developed in the previous section. In particular, we are interested in disentangling the influence of factors from the global, the local and the individual level. To reduce the number of treatments to a manageable number, we have chosen to focus on a number of specific networks. Our main experimental treatment variable consists of four network configurations in which agents interact.

(2002) finds that the global game solution for games with strategic complementarities can be approached by uncertainty about other players' risk aversion. There is to the best of our knowledge no such theory that characterizes a global game solution for anti-coordination games on networks as the one we are interested in.

${ }^{7}$ Comparative static properties can be checked by first verifying that $\frac{\partial e_{i}^{*}}{\partial r}>0$ for given $\sum_{j \in N_{i}} e_{j}$ and then applying the envelope theorem. 
In our experimental set-up we implemented a finitely repeated version of the game proposed and analyzed by Bramoullé and Kranton (2007). ${ }^{8}$ Throughout the experiment we had groups of $N=4$ individuals that formed a connected network $\mathrm{g}$. In the game individuals' pure strategies at each stage are investment levels $e_{i}$. Payoffs at each stage are calculated using the following benefit function from profile e in graph $\mathrm{g}$ :

$$
u_{i}(\mathrm{e}, \mathrm{g})=a \ln \left(1+e_{i}+\sum_{j \in N_{i}} e_{j}\right)-c e_{i}
$$

with $a, c>0$ and $c=\frac{1}{2} a$. This implies that $e^{*}=1$ and that in equilibrium $e_{i}=\max \left\{0,1-\sum_{j \in N_{i}} e_{j}\right\} .^{9}$

As treatments we considered a sequence of four different network structures, of which two structures were regular and two irregular, as depicted in the following figures:
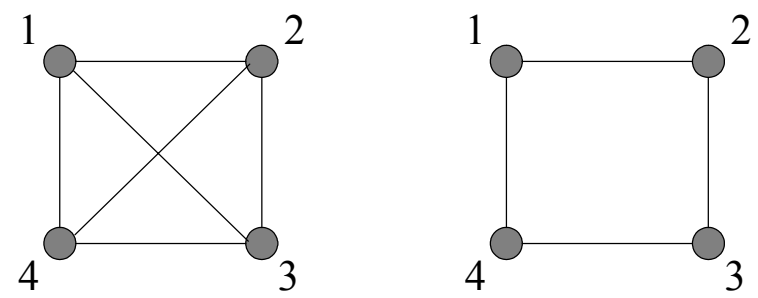

Figure 1: Complete network (1) and circle (2)
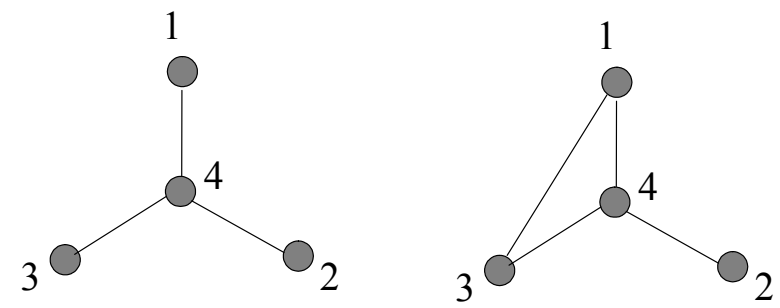

Figure 2: Star network (3) and core-periphery network (4)

\footnotetext{
${ }^{8}$ Note that all static equilibria continue to be equilibria also in the finitely repeated version. In symmetric regular structures players can alternatively play additional equilibrium strategies, such as a trigger strategy, to achieve cooperation in the first stages. This would imply that all players coordinate on a rewarding equilibrium (a distributed profile) in the last stage(s), if all players cooperated or, if one player deviates, the others punish by playing a less favorable equilibrium (they free-ride on the defector). Our empirical analysis reveals that subjects were hardly able to coordinate their play on such a sophisticated level.

${ }^{9}$ In the experiment we set $a=72,13$ and $c=36,07$ (motivated by expositional reasons), which lead to the payoff table in Appendix 2.
} 
For each of these network structures we can characterize the full set of Nash equilibria: In the complete network (1) with $N=4$ and $e^{*}=1$ any profile such that $\sum_{i \in N} e_{i}=1$ constitutes an equilibrium. In the circle network (2) with $N=4$ and $e^{*}=1$ the following strategy profiles constitute Nash equilibria: (i) $(1,0,1,0)$, and (ii) $\left(\frac{1}{3}, \frac{1}{3}, \frac{1}{3}, \frac{1}{3}\right)$. In the star network (3) with $N=4$ and $e^{*}=1$ there are also only two types of Nash equilibria: either the center is a specialist and the agents in the periphery do not invest, or the agents in the periphery are specialists and the center does not invest. Finally, in the core-periphery network (4) with $N=4$ and $e^{*}=1$ there are also only two types of Nash equilibria: either the agent in the periphery invests $e^{*}=1$, the $\mathrm{p}$-core agent linked to this agent does not invest and the remaining core agents invest in total $e^{*}=1$, or only the p-core agent linked to the periphery agent invest $e^{*}=1$ and all other agents do not invest anything.

\subsection{Risk assessment}

We measure risk attitudes in two different ways. First, we register subjects' decisions in a lottery setting, which we implement as a sequence of simple decisions between pairs of alternatives. For each pair, one of the alternatives is a safe payment, the other is a lottery. The sequence of decisions was ordered according to an increasing safe payment while the expected payment of the lottery remained constant. An agent's degree of risk aversion should determine at which decision he is indifferent between the two alternatives and for any further decisions he should prefer the safe alternative.

As an alternative measurement, we combine the experiment with a questionnaire containing Zuckerman's (1994) Sensation Seeking Scale V (SSSV). ${ }^{10}$ This measure is based on the notion that risk taking could be linked to factors that are trans-situational, such as personality traits. The fundamental concept central to most trait theories is that traits are life-long and relatively consistent (Allport (1961)). Risk propensity could thus be more a characteristic of an individual than of the situation. In this area, sensation seeking is found to be of particular importance. Since Zuckerman's et al. (1964) pioneering study, a stream of research has confirmed sensation seekingness as a highly consistent predictor of various kinds of risk taking (Zuckerman (1974), Zuckerman \& Kuhlman (2000), Zaleskiewicz (2001)) with a high reported internal reliability coefficient (Cronbach's alpha ranges from .85 to .90 for all scales).

The SSSV data is gathered via a questionnaire using 40 forced choice items, assessing the respondents' sensation seekingness on four sub-scales: experience seeking (ES), thrill and adventure seeking (TAS), disinhibition

\footnotetext{
${ }^{10}$ We include this well validated questionnaire as an alternative measure, because the predictive validity of expected utility-based assessments of risk attitudes has been questioned, especially when decisions concern low stakes as in experiments. See Harrison et al. (2005) for a systematic review of instruments that measure risk propensity.
} 
(DIS), and boredom susceptibility (BS). The Sensation Seeking Scale V (SSSV) currently is the most widely used form of the sensation seeking scale with the largest volume of normative data supporting it (Zuckerman, 1994). The four sub-scales each have a score range of 0-10 points, with 10 being high. The total scale score is the sum of the sub-scales scores. The thrill and adventure seeking sub-scale examines the respondents' appeal to activities of physical danger or risk taking. In the experience seeking sub-scale desires for new experiences are assessed. Sub-scale items include the desire for exotic travel or association with unusual friends. Items in the disinhibition sub-scale examine respondents' desire to exhibit uninhibited/unrestrained behaviors. These include behaviors considered high risk, such as heavy drinking, drug use, or having a variety of sexual partners. The final subscale, boredom susceptibility, assesses an individual's dislike of repetitive experiences or predictable experiences.

\subsection{Procedural details}

In total eight sessions were run at the experimental laboratory ELSE at Utrecht University in June 2007. Participating subjects came from the subject pool that mainly recruits students of Utrecht University from all faculties. The procedure during the eight sessions was kept the same and all sessions were computerized, using a program written with z-tree (Fischbacher, 1999). 148 subjects participated and were seated in a random order at PCs. Instructions (see Appendix 1) were then read aloud and questions were answered in private. Subjects were randomly assigned to groups of size $\mathrm{N}=4$, but did not know who the other members of their group were. Before starting the experiment, subjects had to answer a few questions concerning their understanding of the rules. The experiment started, when all subjects gave the correct answers to these questions. Throughout the sessions students were not allowed to communicate and could not see others' screens.

In the experiment, subjects played five treatments divided into two different parts. The first part contained a treatment with a block of nine lottery choices. In each block subjects decide between two alternatives, A and B. Alternative A gives a secure payoff that ranges from $€ 10$ to $€ 90$ in steps of $€ 10$. The payoff for a Choice B is either zero or $€ 100$ in each situation. In the lottery setup the payoff for B depends on the result of tossing a coin (at the end of the experiment): if the result of the toss is heads the payoff is zero and if the result is tails the payoff is $€ 100$. The instructions in Appendix 1 show a sample screen of the lottery setup.

The second part contained four treatments, each with a sequence of 20 decision rounds. Each treatment is represented by a specific network structure. After each sequence of 20 decisions, subjects were asked to look at the next network structure. We decided for a partner design where the same four subjects were positioned in four different network structures and 
had to make 80 decisions. The 20 periods per network structure were chosen to allow for coordination of strategies and also to ensure a sufficient number of independent observations on the network level. Although this design is not a direct translation from the original static theoretical setting, we favoured the aspect that it facilitates coordination in this rather complex environment. ${ }^{11}$

In the beginning of each network treatment subjects were informed about their position in the network and that all agents will keep the same network position over all 20 periods played in a network structure. ${ }^{12}$ In each period subjects decided on how much to invest, with investments being any positive number with two decimals in the interval $[0,1]$. Investment resulted in Experimental Currency Units (ECU) that ranged from 0 to 100 (see Appendix 2) with an exchange rate of 0.6 Eurocent per ECU. In the second part of the experiment all investment decisions as well as all payoffs were revealed after each decision to all subjects belonging to the same network and were thus common knowledge.

Afterwards, each subject had to answer a questionnaire asking for personal data and the SSSV. The duration of the experiment was 90 to 120 minutes. Subjects that could not participate because they showed up too late or the lab was full received a show-up fee of $€ 5$. For the first treatment, the lottery, one of the 9 alternatives of one of the participants in the room was selected at random after the experiment and the chosen type of payment was executed. Earning in the second part were calculated from the ECUs subjects earned in that part. This led to minimum earnings of $€ 1.20$ and maximum earnings of $€ 120.90$, with an average payoff of $€ 16.87$ per subject.

The sequence of the treatments for the eight sessions has been motivated by several considerations: We decided for an within-subjects design to relate individual variables (risk attitude) to local and global variables. We run the lottery first in order to avoid effects from experiences in the strategic interaction on individuals' decision. As the result of the lottery was revealed at the end of the experiment we do not expect reverse effects from the lottery to the other treatments. For the other four treatments we first reduced the number of possible combinations (24) to the eight that satisfy the properties that (a) each network structure is equally frequently at a specific position of the sequence in a treatment (each network is twice at each position) and (b) each of the 12 possible pairwise sequences of two different networks is represented equally frequently (i.e. twice) in all sessions. ${ }^{13}$

\footnotetext{
${ }^{11}$ In December 2005 we conducted a pilot experiment with networks of six subjects in a random stranger design. With the exception of our result on risk, all results reported in this paper replicate those of the pilot, which indicates that subjects did not play dynamic strategies in the finitely repeated design.

${ }^{12}$ Within the group of four subjects we ensured that no subject was in a central position for more than one treatment (star center, core center).

${ }^{13}$ See Appendix 3 for selected sequences and the underlying scheme.
} 


\section{Empirical Analysis and Results}

We conducted the experiment with 148 students and the subjects played 20 periods in each of the four networks, resulting in 11840 investment decisions (observations). As we treat the first five periods as trial rounds, the actual sample for analysis consists of 8880 observations. None of the results presented in this paper change qualitatively when we include the first five trial periods in the analyses.

\subsection{Sample description}

Table 1 describes the most important variables of the sample and reports their pairwise correlation. On average, the subjects contributed 0.39 units (with a maximum contribution of 1.0) per period across all sessions and network structures. $66 \%$ of the subjects were female, $20 \%$ did not have the Dutch nationality, $32 \%$ had at least one friend in the same session, and the average age was 22 years. To correct for these and other unobserved individual characteristics we use the variables (4)-(7) as controls and include random effects for all 148 subjects in our estimations.

Table 1: Descriptive statistics and pairwise correlations of subject variables

\begin{tabular}{|c|c|c|c|c|c|c|c|c|c|c|c|c|}
\hline & & $\mathrm{N}$ & mean & s.d. & $\min$ & $\max$ & $(1)$ & (2) & (3) & (4) & (5) & (6) \\
\hline (1) & contribution $^{\$}$ & 8880 & 0.39 & 0.35 & 0 & 1 & 1 & & & & & \\
\hline$(2)$ & lottery & 148 & 40 & 14.38 & 10 & 70 & 0.15 & 1 & & & & \\
\hline (3) & SSSV & 148 & 4.92 & 1.42 & 1.5 & 9.25 & 0.14 & $0.18^{*}$ & 1 & & & \\
\hline (4) & female $^{1}$ & 148 & 0.66 & 0.47 & 0 & 1 & -0.08 & -0.15 & -0.1 & 1 & & \\
\hline$(5)$ & foreign $^{1}$ & 148 & 0.2 & 0.4 & 0 & 1 & 0.01 & 0.06 & -0.08 & -0.01 & 1 & \\
\hline (6) & age & 148 & 22.17 & 4.81 & 16 & 59 & 0.03 & 0.14 & -0.1 & $-0.18^{*}$ & $0.31^{\star \star *}$ & 1 \\
\hline$(7)$ & friendships $^{1}$ & 148 & 0.32 & 0.47 & 0 & 1 & -0.13 & 0.1 & 0.04 & -0.07 & 0.1 & -0.04 \\
\hline
\end{tabular}

As Table 1 also shows, the risk measurement from the lottery treatment ('risk attitude') and the sensation seeking score from the questionnaire ('SSSV') are positively correlated with each other $(\beta=18 \%)$ at a statistically significant level of $<5 \%$. This corroborates our choice of these two variables as related but nevertheless alternative measurements of behavior towards risk. ${ }^{14}$

The subjects in our experiment are on average risk averse as their choice to switch to fixed payments averages at $€ 40$ (with a std. dev. of $€ 14.38$ ), while the risk-neutral, expected value of the lottery is $€ 50$. This corresponds with the sensation seeking measurement (SSSV), which also has a

\footnotetext{
${ }^{14}$ This confirms prior findings that there is indeed a relation between the psychological measurement of risk with the SSSV and economic risk taking (Zuckerman (1974), Zuckerman \& Kuhlman (2000), Zaleskiewicz (2001)).
} 
relative low average value of 4.92 (with a std. dev. of 1.42) compared to the normative sample from Zuckermann (1994) of 5.3. Table 2 reports for every sensation seeking dimension how our sample scored in comparison with the normative sample of Zuckermann (1994) (adjusted to the same ratio of women and men). ${ }^{15}$

Table 2: Sensation seeking values (SSSV scores)

\begin{tabular}{||l|l|l|l||}
\hline \hline & mean (normative) & mean (sample) & s.d. (sample) \\
\hline SSSV-TAS & 6.97 & 6.73 & 2.52 \\
\hline SSSV-ES & 5.13 & 5.72 & 2 \\
\hline SSSV-BS & 3.37 & 2.76 & 1.75 \\
\hline SSSV-DIS & 5.74 & 4.49 & 2.51 \\
\hline SSSV (avg) & 5.3 & 4.92 & 1.42 \\
\hline \hline
\end{tabular}

Table 3 reports structural measures and average contributions at network and at node level. Across the four network structures we can identify seven node types, which are distinctively different from each other, either in their direct or indirect links. These types are star-center, star-periphery, core-center, core-periphery, core-duo (which are the two core nodes without periphery), full and circle. Table 3 characterizes the node types with their degree as a fraction of their maximally possible degrees (Freeman's actor level degree centrality) and their number of directly linked neighbors as a fraction of the maximally possible number (transitivity). At the network level the standard deviation of all nodes' degree centrality determines Freeman's network centrality, the average of all nodes' degree centrality represents the network density, and the average of all nodes' transitivity measures the network clustering.

Graph A in Appendix 4 shows the average profits and contributions per network over time, and Graph B shows the average profits and contributions per node type over time (for all 20 rounds of the experiment). While average investments in the four networks structures diverge over time, average profits converge to roughly the same level. At the node level, differences in profits are rather persistent. Moreover, investments by subjects in the periphery become more and more specialized while we observe an increase in free riding over time for all other node types. An inspection of the average levels of subjects' contributions in Table 3 reveals significant differences between the four network structures: the star clearly has the highest average contribution (0.5), followed by the core (0.39), the circle (0.36) and the full network (0.29). The average contributions of all four networks are statistically different at a significance level of $p<0.001$.

At the node level we find that the star-periphery and core-periphery players contribute the highest amounts (both 0.56 units), while the average

\footnotetext{
${ }^{15}$ The normative sample (age range of $17-23$ years) for the SSSV consisted of 410 male and 807 female undergraduate students from the University of Delaware.
} 
investments of the more central core and star players are significantly lower (all around 0.34 with no statistical difference between each other). As Table 3 shows, circle players invest a small, but significantly higher amount than that (0.36). Contributions in the full network stay the lowest of all, irrespective whether they are compared to other networks structures or specific node types.

Table 3: Structural measures and average contributions

\begin{tabular}{|c|c|c|c|c|c|c|}
\hline $\begin{array}{c}\text { network } \\
\text { level }\end{array}$ & $\begin{array}{l}\text { node } \\
\text { level }\end{array}$ & $\mathrm{N}$ & $\begin{array}{c}\text { degree } \\
\text { centrality }\end{array}$ & $\begin{array}{c}\text { network } \\
\text { centrality }\end{array}$ & transitivity & $\begin{array}{c}\text { average } \\
\text { contribution }\end{array}$ \\
\hline \multicolumn{2}{|l|}{ full } & 2220 & 1.00 & 0.00 & 1.00 & $0.29^{a}$ \\
\hline \multicolumn{2}{|l|}{ circle } & 2220 & 0.67 & 0.00 & 0.00 & $0.36^{a}$ \\
\hline \multicolumn{2}{|l|}{ star } & 2220 & 0.50 & 0.29 & 0.00 & $0.50^{a}$ \\
\hline \multicolumn{2}{|r|}{ center } & 555 & 1.00 & & 0.00 & $0.34^{b}$ \\
\hline \multicolumn{2}{|r|}{ periphery } & 1665 & 0.33 & & 0.00 & $0.56^{b}$ \\
\hline \multicolumn{2}{|l|}{ core } & 2220 & 0.67 & 0.24 & 0.58 & $0.39^{a}$ \\
\hline \multicolumn{2}{|r|}{ core-center } & 555 & 1.00 & & 0.33 & 0.33 \\
\hline \multicolumn{2}{|r|}{ core-duo } & 1110 & 0.67 & & 1.00 & 0.34 \\
\hline \multicolumn{2}{|r|}{ periphery } & 555 & 0.33 & & 0.00 & $0.56^{b}$ \\
\hline \multicolumn{7}{|c|}{$a_{\text {significantly different from all other networks with } \mathrm{p}<0.001}$} \\
\hline
\end{tabular}

\section{$5.2 \quad$ Testing of Hypotheses}

Hypothesis 1:

In order to test Hypothesis 1 we compute the percentage of individual investment decisions with which the players reached an equilibrium. An inspection of the data shows that some subjects do not invest the exact amount required for equilibrium behavior, for instance exactly 1 unit, but something close, e.g. 0.95 or 0.99 units. For robustness we therefore also identify 'fuzzy' equilibria, which allow for some deviations in individual contributions $x$ with $0.9 \leq x \leq 1$ and $0 \leq x \leq 0.1$. Further, for distributed equilibria (e.g. investments of $1 / 3$ in the circle) and cumulative equilibrium investments (e.g. 1 unit in the full), we accept 'fuzzy' values within a band of $+/-10 \%$ (i.e. individual contributions of $1 / 3 * 0.9 \leq x \leq 1 / 3 * 1.1$ in the circle and a total investment of $0.9 \leq x \leq 1.1$ in the full).

In contrast to equilibria, which involve the whole network, coordination may be reached more locally by only some subjects. As a further test of Hypothesis 1 we therefore identify all directly linked subjects that jointly contribute 1 unit. Within this neighborhood we code only those nodes that play 'exact' local coordination to their direct neighbors' investments. Analogously, we also identify 'fuzzy' local coordination within neighborhoods that 
jointly contribute between 0.9 and 1.1 units. The only network where equilibria (at network level) and local coordination (at node level) are identical is the full network, because all nodes are direct neighbors of each other.

Analogously to local coordination we also compute exact and fuzzy myopic best reply. Here we identify all situations where the sum of a subject's current investment and all direct neighbors' investments in the previous period is equal to 1 unit (exact) or between 0.9 and 1.1 units (fuzzy).

Table 4: Frequency of equilibria, local coordination and myopic best response

\begin{tabular}{|c|c|c|c|c|c|c|c|}
\hline \multirow[b]{2}{*}{$\begin{array}{c}\text { network } \\
\text { (type) }\end{array}$} & \multirow[b]{2}{*}{$\begin{array}{c}\mathrm{N} \\
\text { (decisions) }\end{array}$} & \multicolumn{2}{|c|}{ equilibria } & \multicolumn{2}{|c|}{$\begin{array}{c}\text { local coordination } \\
\text { (incl. equilibria) }\end{array}$} & \multicolumn{2}{|c|}{ myopic best reply } \\
\hline & & $\begin{array}{c}\text { exact } \\
(\% \text { of } \mathrm{N})\end{array}$ & $\begin{array}{c}\text { fuzzy } \\
(\% \text { of } N)\end{array}$ & $\begin{array}{c}\text { exact } \\
(\% \text { of } \mathrm{N})\end{array}$ & $\begin{array}{c}\text { fuzzy } \\
(\% \text { of } N)\end{array}$ & $\begin{array}{c}\text { exact } \\
(\% \text { of } \mathrm{N})\end{array}$ & $\begin{array}{c}\text { fuzzy } \\
(\% \text { of } N)\end{array}$ \\
\hline full & 2220 & $5.4 \%$ & $9.0 \%$ & $5.4 \%$ & $9.0 \%$ & $6.9 \%$ & $12.6 \%$ \\
\hline circle & 2220 & $0.4 \%$ & $1.8 \%$ & $6.9 \%$ & $11.8 \%$ & $9.5 \%$ & $17.5 \%$ \\
\hline core & 2220 & $1.3 \%$ & $2.0 \%$ & $8.3 \%$ & $13.0 \%$ & $11.8 \%$ & $18.5 \%$ \\
\hline star & 2220 & $4.7 \%$ & $5.8 \%$ & $20.9 \%$ & $25.8 \%$ & $24.9 \%$ & $30.8 \%$ \\
\hline
\end{tabular}

Table 4 reports for all four network structures the percentage of individual investment decisions that lead to an equilibrium or to local coordination. In support of Hypothesis 1, we find that subjects coordinate on equilibria and also coordinate locally with their direct neighbors in all network types. The percentage of equilibria, of local coordination and of myopic best reply in the star are all higher than in the core-periphery, which again ranks above the circle. Note that we expect to see a relation between the number of potential equilibria and the number of equilibrium observations. On the level of local coordination it seems to be easier to coordinate if there are less equilibria. On the other hand, a higher number of potential equilibria in the full network seems to increase the chance to be in an equilibrium by pure coincidence. Although myopic best reply is played more often than local coordination, the frequency distribution across network types is very similar. ${ }^{16}$ In line with this, all other results in this paper on local coordination and myopic best response are qualitatively identical. In the following we therefore only report results on local coordination.

The full network has the highest percentage of equilibrium decisions. This can be partially explained with the high free-riding behavior that we observe in the full network: $34 \%$ of all contributions are 0 , compared to $21 \%$, $24 \%$ and $18 \%$ for the circle, core-periphery and star, respectively. At the same time $10 \%$ of contributions are 1 . This leads to several equilibria with specialists. In fact, out of 30 periods (with 120 individual decisions) where exact equilibria are reached in the full network (5.4\% of all 555 periods or

\footnotetext{
${ }^{16}$ Appendix 4 shows the frequencies of local coordination (Graph $\mathrm{C}$ ) and of myopic best reply (Graph D) per network and per node type over time (for all 20 rounds of the experiment).
} 
2220 decisions), 19 periods involve specialists $(0,0,0,1)$, one a near-specialist $(0,0,0.1,0.9)$ and ten periods show truly distributed contributions of two or more players. As we will see below, these equilibria are extremely unstable and seem to occur at random in a continuous trial-and-error process and less as a result of a coordinated effort.

Also note that the full network has the lowest percentage of local coordination and myopic best reply. This is an artifact of the special situation that all subjects are direct neighbors of each other in the full network. Hence, in contrast to all other networks with indirect neighbors, local coordination is identical to global coordination and therefore cannot add to the number of equilibria.

\section{Hypothesis 2:}

To test Hypothesis 2 we compute the frequency of 'converging equilibria' in different network structures. In analogy to Callander and Plott (2005) we define convergence as staying in the same equilibrium for at least three consecutive periods, as opposed to the above definition of reaching an equilibrium, i.e. playing it at least in one period.

Table 5: Frequency of converging equilibria

\begin{tabular}{|c|c|c|c|c|c|c|c|}
\hline \multirow{2}{*}{$\begin{array}{c}\text { network } \\
\text { (type) }\end{array}$} & \multirow{2}{*}{$\begin{array}{c}\mathrm{N} \\
\text { (periods) }\end{array}$} & \multicolumn{3}{|c|}{ convergence exact equilibria } & \multicolumn{3}{|c|}{ " convergence fuzzy equilibria } \\
\hline & & (no. eq.) & (no. per) & $(\%$ of $\mathrm{N})$ & (no. eq.) & (no. per) & $(\%$ of $\mathrm{N})$ \\
\hline full & 555 & 0 & 0 & $0 \%$ & 0 & 0 & $0 \%$ \\
\hline circle & 555 & 0 & 0 & $0 \%$ & 1 & 10 & $1.8 \%$ \\
\hline core & 555 & 0 & 0 & $0 \%$ & 0 & 0 & $0 \%$ \\
\hline star & 555 & 4 & 19 & $3.4 \%$ & 4 & 21 & $3.8 \%$ \\
\hline
\end{tabular}

Table 5 shows the frequency of convergence to equilibrium play (no. eq.) as well as the number of periods played in converged equilibria (no. per.). With regard to exact equilibria we only find convergence on the star network, played over a total of 19 periods or $3.4 \%$ of all 555 periods: one group of subjects converged twice (over 3 periods each), and another two groups converged over six and over seven periods, respectively. When including fuzzy equilibria, we also find convergence on the circle. Here one group plays the same equilibrium for 10 periods in a row. In the star, one group stays two periods longer in the fuzzy equilibrium, increasing the total number of periods and decisions taken, but not the occurrence as such.

We find that convergence exclusively involves specialized equilibria. For the star this is obvious as only specialist equilibria exist. Here, the data show that all four converged equilibria are periphery-sponsored with a free-riding center. More importantly, in the circle, where a non-specialist equilibrium could be played, the one observed convergence involves a specialist equilibrium, i.e. an alternating sequence of specialists and free-riders. These 
findings provide support for Hypothesis 2, which predicts that only those specialist equilibria are stable.

Also note that in the full and in the core network none of the equilibria reported in Table 4 is stable enough to satisfy our definition of convergence. This is all the more striking as the full network has the highest number of equilibria. Most of these equilibria, however, have a lifetime of only one period and none of them survives more than two periods in a row.

\section{Hypothesis 3:}

A look back at Table 4 provides univariate support for Hypothesis 3, which predicts a negative relation between local coordination play and density (average node degree centrality) in symmetric regular networks: as expected, the circle has a higher frequency of local coordination than the full network, which has a higher density.

To test Hypothesis 3 in a multiple variable setting we run a panel probit with the sub-sample of regular networks, i.e. full and circle. As shown in Table 6 , the dependent variables are four dummies that take the value 1 for exact and fuzzy local coordination as defined above (Model 1 and 2) and for equilibrium coordination (Model 3 and 4). Next to the variable of interest, network density (average node degree), we include the period as trend control and session fixed effects. In Model 1 and 2 the unit of observation is a subject's individual (local) decision. Hence, we include subjects' individual characteristics and random effects at the subject level. Further, to capture unobserved characteristics at the group level, we include 37 (minus one) fixed effects, one for each group of four subjects within the partner design. In Model 3 and 4 the unit of observation is the (global) coordination of a group of four subjects. We therefore drop all effects at the individual level and include random effects at the group level instead. ${ }^{17}$

\footnotetext{
${ }^{17}$ For robustness, we also estimated Model 3 and 4 with the econometric specification used in Model 1 and 2. The qualitative results remain unchanged.
} 
Table 6: Network density and local/global coordination in regular networks

\begin{tabular}{|c|c|c|c|c|}
\hline $\begin{array}{l}\text { model } \\
\text { dependent }\end{array}$ & $\begin{array}{c}1^{\#} \\
\text { local coord. } \\
\text { (exact) }\end{array}$ & $\begin{array}{c}2^{\#} \\
\text { local coord. } \\
\text { (fuzzy) }\end{array}$ & $\begin{array}{c}3^{\$} \\
\text { equilibrium } \\
\text { (exact) }\end{array}$ & $\begin{array}{c}4^{\$} \\
\text { equilibrium } \\
\text { (fuzzy) }\end{array}$ \\
\hline density [avg degr] & $\begin{array}{l}-0.466^{* *} \\
{[-2.466]}\end{array}$ & $\begin{array}{r}-0.538^{* * *} \\
{[-3.400]}\end{array}$ & $\begin{array}{r}3.417^{\star \star \star} \\
{[4.227]}\end{array}$ & $\begin{array}{r}3.027^{* * *} \\
{[5.413]}\end{array}$ \\
\hline period & $\begin{array}{r}0.031^{* * *} \\
{[4.210]}\end{array}$ & $\begin{array}{r}0.022^{* * *} \\
{[3.519]}\end{array}$ & $\begin{array}{r}0.031 \\
{[1.508]}\end{array}$ & $\begin{array}{r}0.021 \\
{[1.280]}\end{array}$ \\
\hline female & $\begin{array}{r}0.007 \\
{[0.089]}\end{array}$ & $\begin{array}{r}0.021 \\
{[0.328]}\end{array}$ & & \\
\hline foreign & $\begin{array}{r}-0.112 \\
{[-1.146]}\end{array}$ & $\begin{array}{r}-0.057 \\
{[-0.698]}\end{array}$ & & \\
\hline age & $\begin{array}{r}0.011 \\
{[1.350]}\end{array}$ & $\begin{array}{r}0.007 \\
{[0.938]}\end{array}$ & & \\
\hline friends & $\begin{array}{r}0.066 \\
{[1.423]}\end{array}$ & $\begin{array}{r}0.022 \\
{[0.539]}\end{array}$ & & \\
\hline constant & $\begin{array}{r}-1.572^{* \star \star} \\
{[-5.120]}\end{array}$ & $\begin{array}{r}-1.378^{\star \star \star} \\
{[-4.890]}\end{array}$ & $\begin{array}{r}-4.859^{\star \star *} \\
{[-6.042]}\end{array}$ & $\begin{array}{r}-3.993^{\star \star *} \\
{[-6.809]}\end{array}$ \\
\hline $\begin{array}{l}\text { session } \mathrm{FE} \\
\text { group } \mathrm{FE}\end{array}$ & $\begin{array}{c}y \\
y^{*}\end{array}$ & $\begin{array}{r}y \\
y^{* *}\end{array}$ & $y^{*}$ & $y^{* *}$ \\
\hline $\mathrm{N}$ & 4440 & 4440 & 1110 & 1110 \\
\hline chi2 & 132.316 & 156.067 & 28.062 & 39.682 \\
\hline prob > chi2 & 0 & 0 & 0.001 & 0 \\
\hline
\end{tabular}

\# panel probit estimation with random effects for 148 individual subjects

$\$$ panel probit estimation with random effects for 37 groups (4 subjects each)

${ }^{*} p<0.1,{ }^{* *} p<0.05,{ }^{* * *} p<0.01$; t-values in brackets

As Table 6 reports, Model 1 and 2 support Hypothesis 3 in a multiple variable setting. Density is significantly negatively related to local coordination. However, if we run the same estimations with equilibrium play, we find the opposite. Here, density is positively related to equilibrium play. Table 4 also supports this in the univariate setting, where the circle has the lowest percentage of equilibria, compared to the highest percentage of the full network. As equilibrium play is coordination on the whole network, the findings are ambiguous. Hypothesis 3 seems to be only supported when we allow for 'local' coordination, where some players invest optimally within their direct neighborhood, while others in the network do not.

\section{Hypothesis 4:}

Table 7 reports the frequency of free-riding behavior (contribution of 0 ), maximum effort (contribution of 1) and specialized play (contribution of 1 or 0 ) in the star and in the core network. While a greater number of players choose the maximum contribution in the star, the core-periphery network has a higher proportion of free-riders. Although these two effects nearly compensate each other when added up, we nevertheless find that specialized play is more common in the star network. The result indicates some support 
for Hypothesis 4, which predicts a higher probability to play specialized in the star. However, as Table 7 shows, the difference in the proportion of specialized play between the two networks is only $2.5 \%$ (38.8\%-36.3\%). This raises concerns about the robustness of the difference in a multiple variable setting.

Table 7: Frequency of specialization in irregular networks

\begin{tabular}{||cc|c|c|c|c||}
\hline \hline \multirow{2}{*}{$\begin{array}{c}\text { contribution } \\
\text { (type) }\end{array}$} & $\mathrm{N}$ & \multicolumn{2}{|c|}{ core network } & \multicolumn{2}{c||}{ star network } \\
\cline { 3 - 6 }$($ decisions $)$ & $($ no. con) & $(\%$ of N) & (no. con) & $(\%$ of N) \\
\hline con $=0$ & 2220 & 538 & $24.2 \%$ & 407 & $18.3 \%$ \\
\hline con $=1$ & 2220 & 269 & $12.1 \%$ & 455 & $20.5 \%$ \\
\hline con $=0$ or con $=1$ & 2220 & 807 & $36.3 \%$ & 862 & $38.8 \%$ \\
\hline \hline
\end{tabular}

To test the univariate results and Hypothesis 4 in a more robust, multiple variable setting we compute different dummies that take the value 1 for free-riding behavior, for maximum effort contribution, and for specialized behavior. In all three cases the dummies capture exact $(0,1)$ and fuzzy $(\leq 0.1, \geq 0.9)$ contributions separately. For each of the six dummies (as dependent variables) we then estimate a panel probit model using the sample of star and core observations only. The explanatory variable of interest is a dummy indicating decisions in the star network, which we expect to be positively related to the dummy for specialized play. The rest of the econometric specification is identical to Model 1 and 2 in Table 6.

As the results in Table 8 show, the star is negatively related to the probability of free-riding (Model 1 and 2) and positively associated with maximum effort (Model 3 and 4). Although this is in line with the respective univariate findings, the most important test for Hypothesis 4 fails: the star dummy shows no significant association with specialized play (Model 5 and 6 ). In other words, the univariate difference in specialized play is not related to network structure, but to other factors. Note that the fixed effects, random effects (unreported) and some control variables are statistically significant: specialized play (primarily free-riding) is more likely to occur in later periods. ${ }^{18}$ Further, females and subjects with at last one friend in the same session choose maximum effort less often. As both the star and the core are irregular structures, the position of specific players and their individual characteristics matter. Here, they seem to explain the univariate difference in specialized play better than network structure. Hypothesis 4 can therefore not be confirmed.

\footnotetext{
${ }^{18}$ Increased free-riding over time is rather common in public good experiments where investments are complements. It has been attributed either to learning (the absence) of social motives (e.g. by Andreoni (1988)) or to diminishing confusion (e.g. by Houser and Kurzban (2002)) suggesting that individuals gradually come to understand the underlying incentives. Kirchkamp and Nagel (2007) as well as Cassar (2007) find the same decline of cooperation in PD games on networks.
} 
Table 8: Panel probit estimation of specialization in irregular networks

\begin{tabular}{|c|c|c|c|c|c|c|}
\hline \multirow{3}{*}{$\begin{array}{l}\text { model } \\
\text { dependent }\end{array}$} & \multicolumn{2}{|c|}{ Free-riding } & \multicolumn{2}{|c|}{ Maximum effort } & \multicolumn{2}{|c|}{ Specialized } \\
\hline & 1 & 2 & 3 & 4 & $\begin{array}{c}5 \\
\text { con }=0\end{array}$ & $\begin{array}{c}6 \\
\text { con<=0.1 }\end{array}$ \\
\hline & con $=0$ & con $<=0.1$ & $\operatorname{con}=1$ & con $>=0.9$ & $\begin{array}{c}o r \\
\text { con=1 }\end{array}$ & $\begin{array}{c}\text { or } \\
\text { con }>=0.9\end{array}$ \\
\hline \multirow[t]{2}{*}{ star } & $-0.264^{* \star *}$ & $-0.347^{* \star *}$ & $0.438^{* * *}$ & $0.425^{\star \star \star}$ & 0.067 & -0.016 \\
\hline & {$[-5.620]$} & {$[-7.977]$} & [8.007] & [8.406] & {$[1.570]$} & {$[-0.385]$} \\
\hline \multirow[t]{2}{*}{ period } & 0.007 & $0.010^{* \star}$ & 0.006 & 0.005 & $0.011^{* *}$ & $0.014^{\star * *}$ \\
\hline & [1.395] & [2.047] & [1.036] & [0.891] & [2.239] & {$[2.848]$} \\
\hline \multirow[t]{2}{*}{ female } & -0.125 & -0.071 & $-0.384^{* * *}$ & $-0.300 * *$ & $-0.399 * * *$ & $-0.301^{* * *}$ \\
\hline & {$[-0.980]$} & {$[-0.563]$} & {$[-2.616]$} & {$[-2.100]$} & {$[-3.803]$} & {$[-2.806]$} \\
\hline \multirow[t]{2}{*}{ foreign } & -0.23 & -0.191 & 0.12 & 0.074 & -0.079 & -0.071 \\
\hline & {$[-1.395]$} & {$[-1.187]$} & [0.631] & [0.402] & {$[-0.598]$} & {$[-0.530]$} \\
\hline \multirow[t]{2}{*}{ age } & 0.008 & 0.012 & -0.001 & 0 & -0.001 & 0.003 \\
\hline & [0.512] & [0.792] & {$[-0.093]$} & [0.016] & {$[-0.103]$} & [0.264] \\
\hline \multirow[t]{2}{*}{ friends } & 0.062 & 0.088 & $-0.182^{*}$ & $-0.159^{*}$ & -0.07 & -0.031 \\
\hline & {$[0.755]$} & [1.082] & {$[-1.933]$} & {$[-1.744]$} & {$[-1.055]$} & {$[-0.459]$} \\
\hline \multirow[t]{2}{*}{ constant } & $-1.293^{* * *}$ & $-1.016^{\star \star}$ & $-2.677^{* * *}$ & $-2.190^{* * *}$ & $-1.002^{* *}$ & $-0.696^{*}$ \\
\hline & {$[-2.688]$} & {$[-2.155]$} & {$[-3.946]$} & {$[-3.826]$} & {$[-2.520]$} & {$[-1.760]$} \\
\hline session FE & $y$ & $y$ & $y^{* * *}$ & $y^{* *}$ & $\mathrm{y}^{* *}$ & $\mathrm{y}^{* *}$ \\
\hline group FE & $y$ & & $y^{\star * *}$ & $\mathrm{y}^{\star *}$ & $\mathrm{y}^{\star *}$ & $\mathrm{y}^{* *}$ \\
\hline $\mathrm{N}$ & 4440 & 4440 & 4440 & 4440 & 4440 & 4440 \\
\hline chi2 & 80.776 & 99.444 & 178.714 & 167.991 & 222.184 & 171.674 \\
\hline prob > chi2 & 0 & 0 & 0 & 0 & 0 & 0 \\
\hline
\end{tabular}

Probit panel estimation with random effects for 148 individual subjects.

${ }^{*} p<0.1,{ }^{* *} p<0.05,{ }^{* * *} p<0.01$; t-values in brackets

\section{Hypothesis 5 \& 6 :}

Up to this point all hypotheses focused on the effects that the network structure as a whole has on individual players' investment decision. This assumes that every player fully comprehends and anticipates all other players' actions in the network, irrespective whether they are direct neighbors or only indirectly connected. We now take a view that individuals are to some extent boundedly rational and analyze whether the observed investments can be better explained by local factors at the node level.

In the following hypotheses we analyze how the direct neighborhood affects players' investment decisions, while controlling for the general network structure. Hypotheses 5 and 6 predict a negative relation between individual investment and a player's (node) degree centrality and/or transitivity. To test these hypotheses we run panel estimations with random effects for each subject with individual contributions as the dependent. As the experimental design only allows contributions between 0 and 1 (although they could theoretically also be higher or lower than that) we use a Tobit panel model. Next to the explanatory variables of interest, node degree centrality and transitivity, we include (four minus one) network dummies to control for the fixed effects of the whole network structure. The rest of the econometric specification is identical to previous models. 
Table 9: Node degree and transitivity on contribution and local coordination

\begin{tabular}{|c|c|c|c|c|c|c|}
\hline $\begin{array}{l}\text { model } \\
\text { dependent }\end{array}$ & $1^{\#}$ & $\begin{array}{c}2^{\#} \\
\text { ntribution }\end{array}$ & $3^{\#}$ & \multicolumn{3}{|c|}{ local coordination (exact) } \\
\hline degr. centr [node] & $\begin{array}{l}-0.534^{\star \star \star} \\
{[-16.986]}\end{array}$ & & $\begin{array}{l}-0.517^{\star \star \star} \\
{[-16.420]}\end{array}$ & $\begin{array}{l}-1.805^{\star \star \star} \\
{[-13.354]}\end{array}$ & & $\begin{array}{l}-1.813^{\star \star \star} \\
{[-12.465]}\end{array}$ \\
\hline transitivity [node] & & $\begin{array}{r}-0.171^{* * *} \\
{[-6.527]}\end{array}$ & $\begin{array}{r}-0.127^{\star * *} \\
{[-4.890]}\end{array}$ & & $\begin{array}{r}-0.331^{\star * *} \\
{[-3.287]}\end{array}$ & $\begin{array}{r}0.016 \\
{[0.158]}\end{array}$ \\
\hline period & $\begin{array}{r}-0.007^{* * *} \\
{[-5.908]}\end{array}$ & $\begin{array}{r}-0.007^{* * *} \\
{[-5.863]}\end{array}$ & $\begin{array}{r}-0.007^{* * *} \\
{[-5.911]}\end{array}$ & $\begin{array}{r}0.025^{* * *} \\
{[5.300]}\end{array}$ & $\begin{array}{r}0.024^{* * *} \\
{[5.287]}\end{array}$ & $\begin{array}{r}0.025^{* * *} \\
{[5.299]}\end{array}$ \\
\hline female & $\begin{array}{l}-0.072^{*} \\
{[-1.891]}\end{array}$ & $\begin{array}{r}-0.063 \\
{[-1.636]}\end{array}$ & $\begin{array}{c}-0.072^{*} \\
{[-1.915]}\end{array}$ & $\begin{array}{r}-0.032 \\
{[-0.522]}\end{array}$ & $\begin{array}{r}0.008 \\
{[0.106]}\end{array}$ & $\begin{array}{r}-0.032 \\
{[-0.519]}\end{array}$ \\
\hline foreign & $\begin{array}{r}0.013 \\
{[0.275]}\end{array}$ & $\begin{array}{r}0.035 \\
{[0.717]}\end{array}$ & $\left.\begin{array}{r}0.01 \\
{[0.211]}\end{array}\right]$ & $\begin{array}{r}0.013 \\
{[0.172]}\end{array}$ & $\begin{array}{r}0.099 \\
{[1.130]}\end{array}$ & $\begin{array}{r}0.013 \\
{[0.177]}\end{array}$ \\
\hline age & $\begin{array}{r}-0.004 \\
{[-0.818]}\end{array}$ & $\begin{array}{r}-0.003 \\
{[-0.609]}\end{array}$ & $\begin{array}{r}-0.003 \\
{[-0.757]}\end{array}$ & $\begin{array}{r}0.01 \\
{[1.624]}\end{array}$ & $\begin{array}{c}0.014^{*} \\
{[1.814]}\end{array}$ & $\begin{array}{r}0.01 \\
{[1.617]}\end{array}$ \\
\hline friends & $\begin{array}{c}-0.043^{*} \\
{[-1.756]}\end{array}$ & $\begin{array}{l}-0.047^{*} \\
{[-1.896]}\end{array}$ & $\begin{array}{c}-0.042^{*} \\
{[-1.735]}\end{array}$ & $\begin{array}{r}-0.046 \\
{[-1.180]}\end{array}$ & $\begin{array}{r}-0.052 \\
{[-1.147]}\end{array}$ & $\begin{array}{r}-0.046 \\
{[-1.183]}\end{array}$ \\
\hline full & $\begin{array}{l}-0.043^{* *} \\
{[-2.026]}\end{array}$ & $\begin{array}{r}-0.143^{* * *} \\
{[-4.781]}\end{array}$ & $\begin{array}{l}0.076^{* *} \\
{[2.348]}\end{array}$ & $\begin{array}{c}0.181^{*} \\
{[1.840]}\end{array}$ & $\begin{array}{r}-0.505^{\star * *} \\
{[-4.374]}\end{array}$ & $\begin{array}{r}0.17 \\
{[1.415]}\end{array}$ \\
\hline core & $\begin{array}{r}-0.065^{\star * *} \\
{[-4.330]}\end{array}$ & $\begin{array}{r}-0.055^{* * *} \\
{[-2.637]}\end{array}$ & $\begin{array}{r}0.007 \\
{[0.323]}\end{array}$ & $\begin{array}{r}-0.296^{\star * *} \\
{[-5.051]}\end{array}$ & $\begin{array}{r}-0.442^{* * *} \\
{[-6.049]}\end{array}$ & $\begin{array}{r}-0.303^{* * *} \\
{[-4.162]}\end{array}$ \\
\hline circle & $\begin{array}{r}-0.098^{* * *} \\
{[-6.536]}\end{array}$ & $\begin{array}{l}-0.191^{* * *} \\
{[-13.481]}\end{array}$ & $\begin{array}{r}-0.101^{* * *} \\
{[-6.736]}\end{array}$ & $\begin{array}{r}-0.283^{\star * *} \\
{[-4.396]}\end{array}$ & $\begin{array}{l}-0.701^{\star * *} \\
{[-13.199]}\end{array}$ & $\begin{array}{r}-0.281^{\star * *} \\
{[-4.249]}\end{array}$ \\
\hline constant & $\begin{array}{r}1.048^{* \star *} \\
{[7.489]}\end{array}$ & $\begin{array}{r}0.510^{* * *} \\
{[3.701]}\end{array}$ & $\begin{array}{r}1.035^{* * *} \\
{[7.435]}\end{array}$ & $\begin{array}{l}-0.425^{\star} \\
{[-1.853]}\end{array}$ & $\begin{array}{r}-0.693^{* * *} \\
{[-2.938]}\end{array}$ & $\begin{array}{l}-0.421^{*} \\
{[-1.825]}\end{array}$ \\
\hline session FE & $y$ & $\mathrm{y}$ & $\mathrm{y}$ & $\mathrm{y}$ & $\mathrm{y}^{* \star *}$ & $y$ \\
\hline $\begin{array}{l}\text { group FE } \\
\mathrm{N}\end{array}$ & $\begin{array}{r}y \\
8880\end{array}$ & $\begin{array}{r}y \\
8880\end{array}$ & $\begin{array}{r}y \\
8880\end{array}$ & $\begin{array}{r}y^{* *} \\
8880\end{array}$ & $\begin{array}{l}y^{* * *} \\
8880\end{array}$ & $\begin{array}{r}y^{\star *} \\
8880\end{array}$ \\
\hline chi2 & 852.352 & 601.824 & 878.636 & 671.987 & 456.821 & 671.38 \\
\hline prob > chi2 & 0 & 0 & 0 & 0 & 0 & 0 \\
\hline
\end{tabular}

\# Tobit panel estimation with random effects for 148 individual subjects.

$\$$ Probit panel estimation with random effects for 148 individual subjects.

${ }^{*} p<0.1,{ }^{* *} p<0.05,{ }^{* * *} p<0.01$; t-values in brackets

Table 9 shows the results of the panel Tobits on players' individual investments (Models 1-3). ${ }^{19}$ Further, for explorative purposes, Table 9 also reports the results of panel probits on dummies for (exact) local coordination (Models 4-6). The econometric specification of Models 4-6 is identical to Models 1-3.

As expected we find strong and highly significant negative relations between individual investments and node degree centrality and transitivity, irrespective whether the latter are included jointly or separately. Most of the network dummies are also significant, indicating that the general network structure still plays a role. Overall, Hypotheses 5 and 6 are strongly supported.

The relation of node degree centrality and transitivity with the more boundedly rational, local coordination shows a very similar picture (Models

\footnotetext{
${ }^{19}$ For robustness we also estimated (i) ordinary least squares regressions with the same specification as Models 1-3 and (ii) multilevel mixed-effects linear regression models with random effects both at the individual level and at the group level. The qualitative results remain unchanged.
} 
4-6). Not only individual investment, but also successful coordination decreases with the size of the neighborhood (degree centrality) and/or local clustering (transitivity).

Hypothesis 7:

In principle it could be possible that the local structural position of a specific subject leaves little room for effects related to individual risk attitude or sensation seekingness, and vice versa. Further, if both effects play a role, Hypothesis 7 predicts that, on a given position, risk and sensation seeking subjects invest significantly lower amounts.

To test this we run panel Tobit regressions with random effects for each subject with individual contributions as the dependent and several risk and sensation seeking measures as independent variable. To control for all structural effects associated with a subject's network position we include fixed effects for the seven idiosyncratic node types defined in Table 3. The rest of the econometric specification is identical to previous models.

Table 10: Lottery risk and sensation seeking (SSSV) on contribution

\begin{tabular}{|c|c|c|c|c|c|c|}
\hline $\begin{array}{l}\text { model } \\
\text { dependent }\end{array}$ & $\begin{array}{c}1 \\
\text { contribution }\end{array}$ & $\begin{array}{c}2 \\
\text { contribution }\end{array}$ & $\begin{array}{c}3 \\
\text { contribution }\end{array}$ & $\begin{array}{c}5 \\
\text { contribution }\end{array}$ & $\begin{array}{c}6 \\
\text { contribution }\end{array}$ & $\begin{array}{c}7 \\
\text { contribution }\end{array}$ \\
\hline abs. risk & $\begin{array}{r}0.002 \\
{[1.464]}\end{array}$ & & & & & \\
\hline rel. risk (network) & & $\begin{array}{r}0.001 \\
{[1.464]}\end{array}$ & & & & \\
\hline rel. risk (neighbor) & & & $\begin{array}{r}0.002^{* * *} \\
{[2.770]}\end{array}$ & & & \\
\hline abs. SSSV & & & & $\begin{array}{c}0.022^{*} \\
{[1.699]}\end{array}$ & & \\
\hline rel. SSSV (network) & & & & & $\begin{array}{c}0.016^{*} \\
{[1.699]}\end{array}$ & \\
\hline rel. SSSV (neighbor) & & & & & & $\begin{array}{r}0.038^{* * *} \\
{[5.901]}\end{array}$ \\
\hline period & $\begin{array}{r}-0.007^{* * *} \\
{[-5.912]}\end{array}$ & $\begin{array}{r}-0.007^{* * *} \\
{[-5.912]}\end{array}$ & $\begin{array}{r}-0.007^{\star \star *} \\
{[-5.918]}\end{array}$ & $\begin{array}{r}-0.007^{\star * *} \\
{[-5.913]}\end{array}$ & $\begin{array}{r}-0.007^{* * *} \\
{[-5.913]}\end{array}$ & $\begin{array}{r}-0.007^{* * *} \\
{[-5.924]}\end{array}$ \\
\hline female & $\begin{array}{c}-0.069^{\star} \\
{[-1.829]}\end{array}$ & $\begin{array}{c}-0.069^{\star} \\
{[-1.829]}\end{array}$ & $\begin{array}{c}-0.067^{*} \\
{[-1.795]}\end{array}$ & $\begin{array}{r}-0.058 \\
{[-1.513]}\end{array}$ & $\begin{array}{r}-0.058 \\
{[-1.513]}\end{array}$ & $\begin{array}{r}-0.037 \\
{[-0.976]}\end{array}$ \\
\hline foreign & $\begin{array}{r}0.006 \\
{[0.131]}\end{array}$ & $\begin{array}{r}0.006 \\
{[0.131]}\end{array}$ & $\begin{array}{r}0.006 \\
{[0.126]}\end{array}$ & $\begin{array}{r}0.017 \\
{[0.351]}\end{array}$ & $\begin{array}{r}0.017 \\
{[0.351]}\end{array}$ & $\begin{array}{r}0.023 \\
{[0.488]}\end{array}$ \\
\hline age & $\begin{array}{r}-0.003 \\
{[-0.781]}\end{array}$ & $\begin{array}{r}-0.003 \\
{[-0.781]}\end{array}$ & $\begin{array}{r}-0.003 \\
{[-0.817]}\end{array}$ & $\begin{array}{r}-0.003 \\
{[-0.675]}\end{array}$ & $\begin{array}{r}-0.003 \\
{[-0.675]}\end{array}$ & $\begin{array}{r}-0.002 \\
{[-0.522]}\end{array}$ \\
\hline friends & $\begin{array}{c}-0.045^{\star} \\
{[-1.881]}\end{array}$ & $\begin{array}{c}-0.045^{\star} \\
{[-1.881]}\end{array}$ & $\begin{array}{l}-0.045^{\star} \\
{[-1.871]}\end{array}$ & $\begin{array}{c}-0.043^{*} \\
{[-1.815]}\end{array}$ & $\begin{array}{c}-0.043^{*} \\
{[-1.815]}\end{array}$ & $\begin{array}{c}-0.042^{*} \\
{[-1.713]}\end{array}$ \\
\hline constant & $\begin{array}{r}0.684^{* \star *} \\
{[4.394]}\end{array}$ & $\begin{array}{l}0.264^{\star *} \\
{[1.963]}\end{array}$ & $\begin{array}{r}0.707^{* * *} \\
{[5.159]}\end{array}$ & $\begin{array}{l}0.378^{\star *} \\
{[2.345]}\end{array}$ & $\begin{array}{r}0.824^{\star \star *} \\
{[5.922]}\end{array}$ & $\begin{array}{r}0.209 \\
{[1.531]}\end{array}$ \\
\hline node FE & $y^{* * *}$ & $y^{* * *}$ & $y^{* * \star}$ & $y^{* * *}$ & $y^{* * *}$ & $y^{* * *}$ \\
\hline session FE & $y$ & $y$ & $y$ & $y$ & $y$ & $y^{*}$ \\
\hline $\begin{array}{l}\text { group FE } \\
\mathrm{N}\end{array}$ & $\begin{array}{r}y \\
8880\end{array}$ & $\begin{array}{r}y \\
8880\end{array}$ & $\begin{array}{r}y \\
8880\end{array}$ & $\begin{array}{r}y \\
8880\end{array}$ & $\begin{array}{r}y \\
8880\end{array}$ & $\begin{array}{r}y \\
8880\end{array}$ \\
\hline chi2 & 887.459 & 887.459 & 892.684 & 888.473 & 888.473 & 919.124 \\
\hline prob > chi2 & 0 & 0 & 0 & 0 & 0 & 0 \\
\hline
\end{tabular}

Tobit panel estimation with random effects for 148 individual subjects

${ }^{*} p<0.1,{ }^{* *} p<0.05,{ }^{* * *} p<0.01$; t-values in brackets 
The results in Table 10 show that the absolute risk attitude from the lottery treatment (Model 1) has no association with individual investment levels. The same applies to relative risk levels, where the average absolute risk attitude of all other players in the network is deducted from the absolute risk attitude of the observed player (Model 2). However, a more local relative risk measure that deducts the average risk attitude of the direct neighbors from the risk value of the observed player (Model 3) clearly contradicts Hypothesis 7. This result is also confirmed with the sensation seeking value (SSSV) in Models 4-6. Here, even the absolute SSSV (Model 4) and SSSV in relation to the average of the network (Model 5) are slightly significant, but the statistically and economically strongest influence is, again, detected for the SSSV in relation to the local neighborhood. All results in Table 10 are qualitatively robust with respect to (i) ordinary least squares regressions and (ii) multilevel mixed-effects regressions with random effects for subjects and groups. ${ }^{20}$ This finding suggests some subjects aim at cooperation in a repeated interaction. We can argue in line with Boone et al. (1999, p. 352) that the agent "who tries to induce the other party to cooperate, runs the risk to end up as the sucker". This would imply that relatively more risk loving subjects are more likely to try to play cooperatively. ${ }^{21}$

In an attempt to summarize these results we can claim support for a more 'boundedly rational version' of Hypothesis 7, while sensation seekingness also confirms the hypothesis more generally.

\section{Conclusion}

The aim of this paper is to better understand how individuals' contributions to a local public good depend on the global and the local structure of the neighborhood they are positioned in and to what extend individual factors, like risk attitudes, also have an affect. In the experiment we concentrated on very simple regular as well as irregular network structures, being characterized by different levels of degree centrality and/or transitivity.

We find that individual behavior is significantly affected by the network characteristics both on the global and on the local level. Individuals find it difficult to coordinate on equilibria in regular networks, while in an extremely irregular structure they succeed more frequently. If play converges to an equilibrium (which happens only in $5 \%$ of all cases) it converges to the theoretically predicted equilibria. On the local level we find that a

\footnotetext{
${ }^{20}$ In unreported estimations, we find no interaction effect of risk or SSSV with dummies for regular (vs. irregular) networks. Furthermore, lottery risk shows no interaction effect with period, while relative SSSV (neighbor) has a weak negative interaction effect with period on contribution $(\beta=-0.001 ; t=-1.71 ; p<0.1)$.

${ }^{21}$ As pointed out before this is the only result that is in contrast to our findings from the pilot experiment, in which subjects were in a random stranger design and thus closer to the one-shot situation. There we found a significant negative relation between risk attitude and investment.
} 
larger neighborhood (higher degree) leads to more free riding, which is in line with findings of experiments on cooperative behavior that neglect the neighborhood structure. The same negative effect on investment we find for an increasing transitivity (local clustering) of an individual's neighborhood. Finally, we find that also individual risk attitudes have an effect. Risk averse individuals tend to invest less, although this effect is only present when considering risk aversion relative to direct neighbors. Hence, global, local and individual effects coexist so that decision making by individuals is also affected by the local structure of their neighborhood (as particularly shown in Hypotheses 5, 6 and 7).

In general, these findings suggest that individual play in networks is boundely rational in the sense that coordination is strongly influenced by local and individual factors. Although all subjects had complete information about the whole network structure and although these structures were quite simple, the subjects behave as if they were only partially informed about the global picture. This finding suggests that in order to understand behavior on networks, theory should focus on models with incomplete information about the global structure, such as, e.g., Galeotti et al. (2006). The finding also suggests that valuable predictions can be derived from theoretical models that are confined to the analysis of very simple structures as the basic building blocks for more complex networks.

There are several interesting avenues for future research in this area. A first extension of this research could be to analyze the dynamics of individual decision making in our framework. As coordination seems to be so difficult in this setting, how can we describe learning processes that lead to coordinated behavior in networks and how do they relate to specific structural features? A second extension could be to experimentally explicitly focus on the effect of incomplete information in the local public good framework, as a test of Galeotti et al. (2006) and a follow-up on Berninghaus' et al. (1998, 2002) finding that structure has an effect even if individuals are not informed about it. Finally, also in the framework of local public goods, a dynamic analysis that includes strategic linking between agents could investigate the coevolution of behavior and network structure. 


\section{Appendix 1}

\section{Instructions}

Thank you for participating in this research project. Your earning depends on your decisions and the decisions of the other participants. From now on until the end of the experiment you are not allowed to communicate with each other. If you have some question, raise your hand and one of the instructors will answer the question in private. Please, do not ask aloud. Thank you very much.

The rules are equal for all the participants.

The project consists of 3 phases. In the first phase you will have to decide between different risky or riskless options. The second phase consists of 4 situations. Each situation is independent of the other. In each situation you have to make a sequence of 20 decisions. Your payment at the end depends on these decisions. In the third phase we ask you to fill out a questionnaire.

\section{The Experiment}

\section{Phase I}

In the first phase you will have to decide between 9 pairs of alternatives. As you see below, for each pair, one of the alternatives is a safe payment (A), the other is a lottery (B). After the experiment, one of the 9 alternatives of one of the participants in the room will be selected at random and the chosen type of payment will be executed.

\begin{tabular}{|c|c|c|}
\hline CHOICE A: safe payment & CHOOSE BETWEEN A and B & CHOICE B: lottery (flipping a coin) \\
\hline receive $€] 0_{1}$ - as safe payment & $A \subset C B$ & win $€ 100$ or $€ 0$, with $50 \%$ chance each \\
\hline receive $€ 20$, as safe payment & $A C C B$ & win $€ 100$ or $€ 0$, with $50 \%$ chance each \\
\hline receive $€ 30$, as safe payment & $A<C B$ & win $€ 100$ or $€ 0$, with $50 \%$ chance each \\
\hline receive $€ 40$, - as safe payment & $A \cos \theta$ & win $€ 100$ or $€ 0$, with $50 \%$ chance each \\
\hline receive $€ 50$,- as safe payment & $A C C B$ & win $€ 100$ or $€ 0$, with $50 \%$ chance each \\
\hline receive $€ 60$,- as safe payment & $A \subset C B$ & win $€ 100$ or $€ 0$, with $50 \%$ chance each \\
\hline receive $€ 70$, as safe payment & $A \subset C B$ & win $€ 100$ or $€ 0$, with $50 \%$ chance each \\
\hline receive $€ 80$, - as safe payment & $\wedge \subset C \theta$ & win $€ 100$ or $€ 0$, with $50 \%$ chance each \\
\hline receive $€ 90$, as safe payment & $A C C B$ & win $€ 100$ or $€ 0$, with $50 \%$ chance each \\
\hline & & ок \\
\hline
\end{tabular}


Thus, for EACH of the 9 alternatives (rows) shown, please decide between a safe payment (choice A: "safe") and flipping a coin for $€ 100,-$ (choice B: "lottery"). If you start with choice B ("lottery"), please look carefully at which row you are switching to choice A ("safe").

After this first phase we will announce the beginning of the following second phase:

\section{Phase II}

In the second phase you will be in four different "situations" for 20 periods each. Each situation is represented by a specific network structure that will be shown to you. After 20 periods you will be asked to look at the next network structure. Altogether, you will be in four different network structures and you will have to make 80 decisions.

During this second phase you will be playing with three other randomly chosen participants. In the beginning of each situation you will be informed about your position in the network and you will keep the same network position over all 20 periods played in a network structure. All other members will also not change their identity and positions in the network. Although the network structure and the network positions of the individual players change after each sequence of 20 periods, the persons within your network remain the same over all 80 periods.

The procedure for all 80 periods and all situations/networks is the following:

1. On the computer screen you will be asked to look at a network structure with a specific number, which you will find in the handout. You will also see on the computer screen which player (node number $=$ position) you are in that network. Look carefully at the entire network structure!

2. Each player can produce know-how that will earn him or her Experimental Currency Units (ECUs). You have to decide how much to contribute to the production of know-how. For this you have to type in your "contribution" as any number between 0 and 1, e.g. 0,1 or 0,25 or 0,3 or 0,33 or 0,5 or 0,75 , or 0,8 . . etc. up to 1 .

3. IMPORTANT: Your know-how is available to your direct neighbors, and the know-how of your direct neighbors will be available to you. Your direct neighbors are players with a direct connection to you. On the basis of this total know-how (yours and your direct neighbors') your and your neighbors' ECUs are calculated.

4. Thus, the number of ECUs that you can receive from "know-how" production in each period depends not only on your own contribution 
but also on the contribution of your direct neighbors. Please have a look at Table 1 to see how the ECUs you can earn change with the contribution of yourself and your direct neighbors.

\section{Payment:}

At the end of the experiment, your ECUs earned in the experiment will be converted into Eurocents with an exchange rate of 0,6. Hence, 100 ECUs will be 60 Eurocents. All information which leads to the calculation of your payment will be made transparent.

\section{Phase III (Questionnaire)}

In the third phase we ask you to fill in a questionnaire. All data will be treated confidential and are only used for research. To prove our spending in case of financial investigation, we must ask you for your name and address. These data will be stored separately from the others.

Once you completed the questionnaire, we pay you the amount that you earned in the experiment.

To make sure that everybody understands the rules of the game, we ask you some questions about the game.

\section{Quiz}

Before the experiment started, subjects had to answer a few questions on the experimental setup and rules.

\section{Appendix 2}

Payoff matrix in the hand-out for the experiment:

\begin{tabular}{|c|c|c|c|c|c|c|c|c|c|c|c|c|c|c|}
\hline \multirow{9}{*}{$\begin{array}{l}\text { Sum of your } \\
\text { neighbours' } \\
\text { contribution } \\
\text { (neighbours = } \\
\text { players with a } \\
\text { direct link to } \\
\text { you) }\end{array}$} & \multicolumn{5}{|c|}{ Your own contribution } & \multirow[b]{2}{*}{0.30} & \multirow[b]{2}{*}{0.40} & \multirow[b]{2}{*}{0.50} & \multirow[b]{2}{*}{0.60} & \multirow[b]{2}{*}{0.70} & \multirow[b]{2}{*}{0.75} & \multirow[b]{2}{*}{0.80} & \multirow[b]{2}{*}{0.90} & \multirow[b]{2}{*}{1.00} \\
\hline & & 0.00 & 0.10 & 0.20 & 0.25 & & & & & & & & & \\
\hline & 0.00 & 0.00 & 3.27 & 5.94 & 7.08 & 8.11 & 9.84 & 11.21 & 12.26 & 13.03 & 13.32 & 13.55 & 13.84 & 13. \\
\hline & 0.10 & 6.88 & 9.54 & 11.71 & 12.63 & 13.45 & 14.82 & 15.87 & 16.64 & 17.15 & 17.33 & 17.45 & 17.54 & 17. \\
\hline & 0.20 & 13.15 & 15.32 & 17.06 & 17.79 & 18.43 & 19.48 & 20.24 & 20.76 & 21.05 & 21.12 & 21.15 & 21.06 & 20.8 \\
\hline & 0.25 & 16.10 & 18.04 & 19.59 & 20.23 & 20.79 & 21.70 & 22.33 & 22.74 & 22.93 & 22.95 & 22.93 & 22.76 & 22. \\
\hline & 0.30 & 18.93 & 20.66 & 22.03 & 22.60 & 23.08 & 23.85 & 24.37 & 24.66 & 24.75 & 24.73 & 24.67 & 24.41 & 24. \\
\hline & 0.40 & 24.27 & 25.64 & 26.69 & 27.11 & 27.46 & 27.97 & 28.27 & 28.36 & 28.27 & 28.17 & 28.02 & 27.62 & 27. \\
\hline & 0.50 & 29.25 & 30.30 & 31.06 & 31.35 & 31.58 & 31.87 & 31.97 & 31.88 & 31.63 & 31.45 & 31.23 & 30.69 & 30. \\
\hline & 0.60 & 33.90 & 34.67 & 35.19 & 35.36 & 35.48 & 35.57 & 35.49 & 35.23 & 34.83 & 34.58 & 34.30 & 33.64 & 32. \\
\hline & 0.70 & 38.28 & 38.79 & 39.09 & 39.16 & 39.18 & 39.09 & 38.84 & 38.44 & 37.90 & 37.59 & 37.24 & 36.46 & 35. \\
\hline & 0.75 & 40.37 & 40.77 & 40.96 & 40.98 & 40.96 & 40.79 & 40.46 & 39.99 & 39.39 & 39.05 & 38.67 & 37.84 & 36. \\
\hline & 0.80 & 42.40 & 42.69 & 42.79 & 42.76 & 42.70 & 42.45 & 42.05 & 41.51 & 40.85 & 40.47 & 40.07 & 39.19 & 38.2 \\
\hline & 0.90 & 46.30 & 46.39 & 46.31 & 46.20 & 46.05 & 45.65 & 45.12 & 44.46 & 43.68 & 43.25 & 42.79 & 41.81 & 40.7 \\
\hline & 1.00 & 50.00 & 49.91 & 49.66 & 49.48 & 49.26 & 48.72 & 48.06 & 47.28 & 46.40 & 45.92 & 45.42 & 44.34 & 43. \\
\hline & 1.50 & 66.10 & 65.32 & 64.43 & 63.95 & 63.45 & 62.38 & 61.21 & 59.97 & 58.66 & 57.97 & 57.27 & 55.82 & 54 \\
\hline & 2.00 & 79.25 & 78.01 & 76.69 & 76.00 & 75.30 & 73.85 & 72.33 & 70.76 & 69.13 & 68.29 & 67.45 & 65.71 & 63. \\
\hline & 2.50 & 90.37 & 88.79 & 87.16 & 86.33 & 85.48 & 83.75 & 81.97 & 80.14 & 78.27 & 77.32 & 76.36 & 74.41 & 72. \\
\hline & 3.00 & 100.00 & 98.17 & 96.31 & 95.36 & 94.40 & 92.45 & 90.46 & 88.44 & 86.39 & 85.35 & 84.30 & 82.18 & 80. \\
\hline
\end{tabular}




\section{Appendix 3}

Sequence of treatments per session:

- Session 1: circle - full - star - core

- Session 2: core- star - full - circle

- Session 3: full - core - circle - star

- Session 4: star - circle - core - full

- Session 5: core - circle - star - full

- Session 6: full - star - circle - core

- Session 7: circle - full - core - star

- Session 8: star - core - full - circle

This scheme implies that each network is equally frequently at the first, the second, the third and the fourth position in a treatment and that each sequence of two different networks is equally frequent ( with circle $=1$, full $=2$, $\operatorname{star}=3$, $\operatorname{core}=4)$ :

\begin{tabular}{||l|l|l|l||}
\hline \hline session & 1st pair & 2nd pair & 3rd pair \\
\hline 1 & 12 & 23 & 34 \\
\hline 2 & 43 & 32 & 21 \\
\hline 3 & 24 & 41 & 13 \\
\hline 4 & 31 & 14 & 42 \\
\hline 5 & 41 & 13 & 32 \\
\hline 6 & 23 & 31 & 14 \\
\hline 7 & 12 & 24 & 43 \\
\hline 8 & 34 & 42 & 21 \\
\hline \hline
\end{tabular}




\section{Appendix 4}

Graph A: Average profit and contribution per network over time:
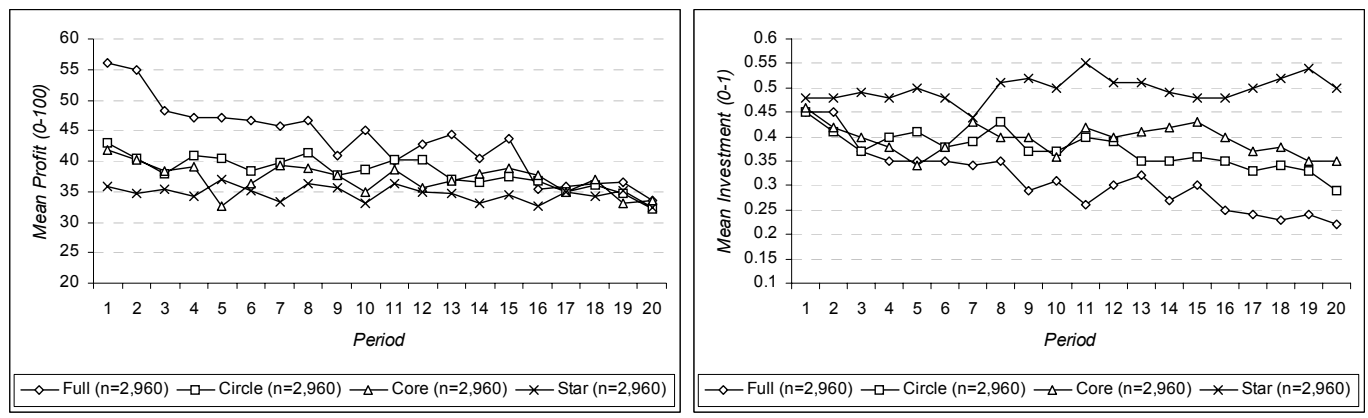

Graph B: Average profit and contribution per node type over time:
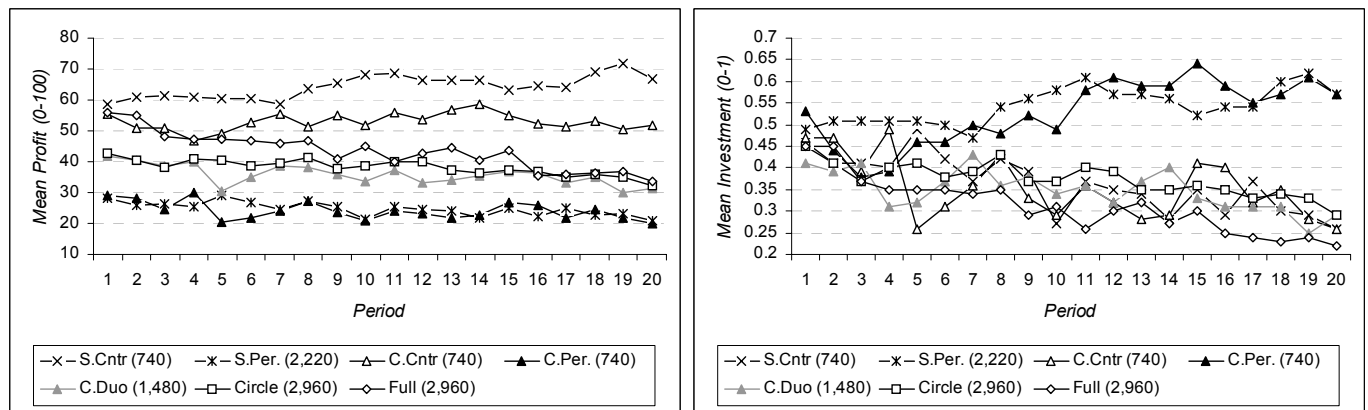

Graph C: Percentage of (exact) local coordination per network / node type over time:
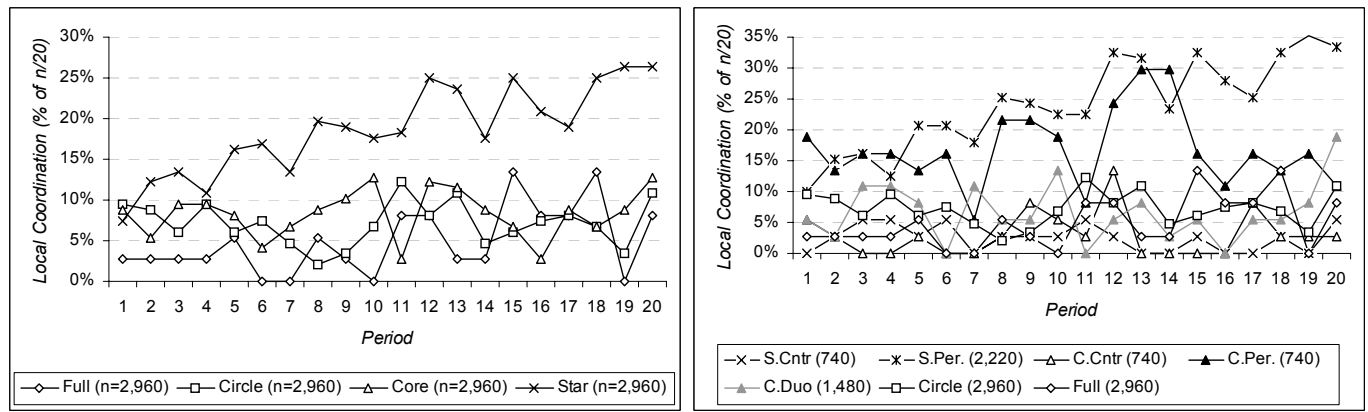

Graph D: Percentage of (exact) myopic best reply per network / node type over time:
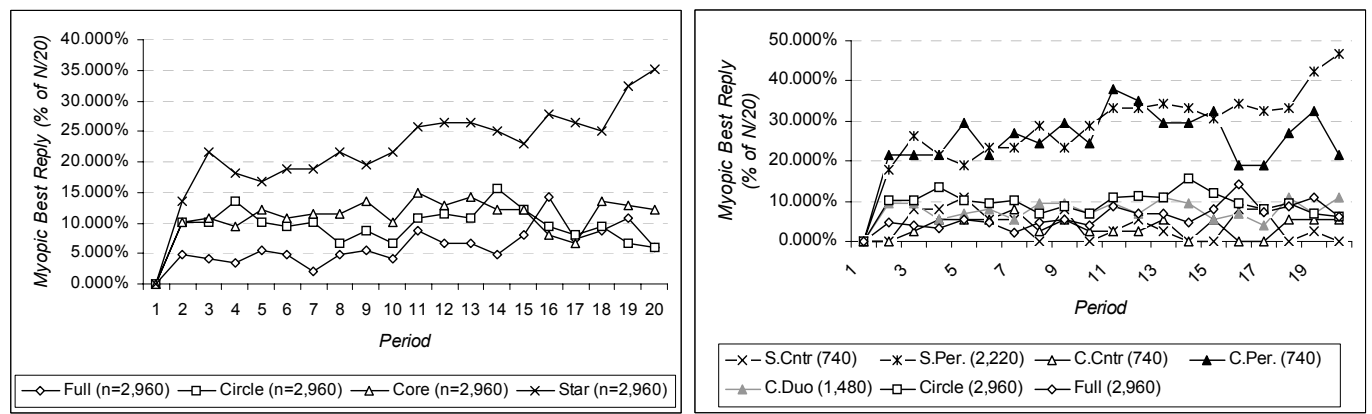


\section{References}

Allport, G. (1961) The Person in Psychology. Boston: Beacon Press

Anderson, S. P., Goeree, J. K., and C. A. Holt (2001) Minimum-Effort Coordination Games: Stochastic Potential and Logit Equilibrium, Games and Economic Behavior 34, 177-199

Andreoni, J. (1988) Why Free Ride? Strategies and Learning in Public Goods Experiments, Journal of Public Economics 37, 291-304,

Berninghaus, S. K., Schwalbe, U. (1996), Conventions, Local Interaction and Automata Networks, Journal of Evolutionary Economics 6, 313324 .

Berninghaus, S., Ehrhart, K.-M. and C. Keser (1998), Coordination and Local Interaction: Experimental Evidence, Economics Letters 58, 269 275 .

Berninghaus, S., Ehrhart, K.-M. and C. Keser (2002), Conventions and Local Interaction Structures: Experimental Evidence, Games and Economic Behavior 39, 177-205.

Blume, L.E. (1993), The Statistical Mechanics of Strategic Interaction, Games and Economic Behavior 5, 387-424.

Boun My, K., Willinger M. and A. Ziegelmeyer (2001), Global versus Local Interaction in Coordination Games: an Experimental Investigation; Working Paper BETA 9923

Boone, C., De Brabander B. and A. van Witteloostuijn (1999) The Impact of Personality on Behavior in Five Prisoner's Dilemma Games, Journal of Economic Psychology 20 (3), 343-377

Bramoullé, Y. and Kranton, R. (2005), Strategic Experimentation, mimeo

Bramoullé, Y. and Kranton, R. (2007), Public Goods in Networks , Journal of Economic Theory 135, 478-494

Buskens, V. Corten, R. and J. Weesie (2007), Consent or Conflict: Coevolution of Coordination and Networks, mimeo.

Callander, S., Plott C.R. (2005), Principals of Network Development and Evolution: An Experimental Study, Journal of Public Economics 89, 1469-1495.

Carlsson, H., van Damme, E. (1993), Global Games and Equilibrium Selection, Econometrica 61, 989-1018. 
Cassar, A. (2007), Coordination and Cooperation in Local, Random and Small World Networks: Experimental Evidence, Games and Economic Behavior 58, 209-230

Chamberlin, J. (1974), Provision of Collective Goods As a Function of Group Size, The American Political Science Review 68 (2), 707-716.

Costa-Gomes, M. A., Crawford, V. P. and B. Broseta (2001), Cognition and Behavior in Normal-Form Games: An Experimental Study, Econometrica 69 (5), 1193-1235

Ellison, G. (1993), Learning, Local Interaction, and Coordination, Econometrica 61, 1047-1071.

Eshel, I., Samuelson, L. and A. Shaked (1998), Altruists, Egoists and Hooligans in a Local Interaction Model, American Economic Review 88, $157-179$.

Fischbacher, U. (1999), z-Tree 1.1.0.: Experimenter's Manual, University of Zurich, Institute for Empirical Research in Economics, http://www. iew.unizh.ch/ztree/index.php.

Foster, A. D., Rosenzweig, M. R. (1995), Learning by Doing and Learning from Others: Human Capital and Technical Change in Agriculture, Journal of Political Economy 103(6), 1176-1209.

Galeotti, A., Goyal, S., Jackson, M. O., Vega-Redondo, F. and L. Yariv (2006), Network Games, mimeo.

Goeree, J. K., Riedl, A. and A. Ule (2008), In Search of Stars: Network Formation among Heterogeneous Agents, mimeo.

Harrison, R. (2003), Equilibrium Selection in Global Games with Strategic Substitutes, mimeo.

Harrison, J. D., Young, J. M., Butow, P., Salkeld, G. and M. J. Solomon (2005), Is it worth the risk? A systematic review of instruments that measure risk propensity for use in the health setting, Social Science 83 Medicine 60 (6), 1385-1396.

Heinemann, F., Nagel, R. and P. Ockenfels (2004a), Global Games on Test: Experimental Analysis of Coordination Games with Public and Private Information, Econometrica 72, 1583-1599.

Heinemann, F., Nagel, R. and P. Ockenfels (2004b), Measuring Strategic Uncertainty in Coordination Games, mimeo.

Hellwig, C. (2002), Imperfect common knowledge of preferences in coordination games, mimeo, UCLA. 
Houser, D., Kurzban, R. (2002) Revisiting Kindness and Confusion in Public Goods Experiments, American Economic Review 92 (4), 1062-1069.

Jackson, M. O. (2005), The Economics of Social Networks, Based on a lecture, to appear in the Proceedings of the 9th World Congress of the Econometric Society, edited by Richard Blundell, Whitney Newey, and Torsten Persson, Cambridge University Press

Kagel, J., Roth, A. (1995), The Handbook on Experimental Economics, Princeton University Press

Kandori, M., Mailath, G. J.and R. Rob (1993), Learning, Mutation and Long Run Equilibria in Games, Econometrica 61, 29-56.

Keser, C., Ehrhart, K.-M. and S.K. .Berninghaus (1998), Coordination and Local Interaction: Experimental Evidence, Economics Letters 58, 269-275.

Kirchkamp, O., Nagel, R. (2007), Naive Learning and Cooperation in Network Experiments, Games and Economic Behavior 58, 269-292

Kosfeld, M. (2002), Stochastic Strategy Adjustment in Coordination Games, Economic Theory 20, 321-339.

Kosfeld, M. (2004), Economic Networks in the Laboratory: A Survey, Review of Network Economics 3, 20-41.

Morris, S. (2000), Contagion, Review of Economic Studies 67, 57-79.

Morris, S., Shin, H. S. (2000) Global Games: Theory and Applications, in: M. Dewatripont, L. Hansen and S. Turnovsky, eds., Advances in Economics and Econometrics, the Eighth World Congress, Cambridge University Press.

Ochs, J. (1995), Coordination Problems, in Kagel, J. H. and A. E. .Roth, eds., Handbook of Experimental Economics, Princeton University Press, $195-251$.

Stahl, D.O., Wilson, P. W. (1995) On players' models of other players: Theory and experimental evidence, Games and Economic Behavior $10,218-254$

Van Huyck, J. B., Battalio, R. C. and R. O. Beil (1990), Tacit Coordination Games, Strategic Uncertainty, and Coordination Failure, American Economic Review 80, 234-249.

Young, H. P .P. (1993), The Evolution of Conventions, Econometrica 61, $57-84$. 
Zaleskiewics, T. (2001), Beyond Risk Seeking and Risk Aversion: Personality and the Dual Nature of Economic Risk Taking, European Journal of Personality 15, 105-122.

Zuckerman, M. (1994). Behavioral Expressions and Biosocial Bases of Sensation Seeking. New York: Cambridge University Press .

Zuckerman, M., Kolin, E. A. Price, L. and I. Zoob (1964). Development of a sensation seeking scale. Journal of Consulting Psychology 28, 477 482.

Zuckerman, M. (1974). The sensation-seeking motive. In B. Maher (Ed.), Progress in experimental personality research (Vol. 7, 79-148). New York: Academic Press.

Zuckerman, M., Kuhlman D. M. (2000), Personality and Risk-taking: Common Biosocial Factors, Journal of Personality 68, 999-1029. 